\title{
Why Are They Wrong? Exploring Surrogates' Accuracy When Predicting Patient Treatment Preferences
}

\author{
RACHAEL LYNN SPALDING \\ rls0046@mix.wvu.edu
}

Follow this and additional works at: https://researchrepository.wvu.edu/etd

Part of the Clinical Psychology Commons, Geropsychology Commons, and the Health Psychology Commons

\section{Recommended Citation}

SPALDING, RACHAEL LYNN, "Why Are They Wrong? Exploring Surrogates' Accuracy When Predicting Patient Treatment Preferences" (2020). Graduate Theses, Dissertations, and Problem Reports. 7961. https://researchrepository.wvu.edu/etd/7961

This Dissertation is protected by copyright and/or related rights. It has been brought to you by the The Research Repository @ WVU with permission from the rights-holder(s). You are free to use this Dissertation in any way that is permitted by the copyright and related rights legislation that applies to your use. For other uses you must obtain permission from the rights-holder(s) directly, unless additional rights are indicated by a Creative Commons license in the record and/ or on the work itself. This Dissertation has been accepted for inclusion in WVU Graduate Theses, Dissertations, and Problem Reports collection by an authorized administrator of The Research Repository @ WVU. For more information, please contact researchrepository@mail.wvu.edu. 
Why Are They Wrong? Exploring surrogates' accuracy when predicting patient treatment preferences

\author{
Rachael L. Spalding, M.S. \\ Dissertation submitted \\ to the Eberly College of Arts and Sciences \\ at West Virginia University \\ in partial fulfillment of the requirements for the degree of \\ Doctor of Philosophy \\ in \\ Psychology
}

Barry Edelstein, Ph.D., Chair

Jonell Strough, Ph.D.

Kevin Larkin, Ph.D.

Kristina Hash, Ph.D.

Department of Psychology

Morgantown, West Virginia

2020

Keywords: end-of-life care, surrogate decision making, medical decision making, surrogate decision-making accuracy

Copyright 2020 Rachael Spalding 


\begin{abstract}
Why are they Wrong: Exploring surrogates' accuracy when predicting patient treatment preferences
\end{abstract}

\title{
Rachael Spalding
}

Surrogate decision making is common in medical settings, particularly regarding treatment decisions for patients at end-of-life. When making decisions on behalf of patients, surrogates are most often encouraged to use the substituted judgment standard and make the decision that the patient would make if he or she were able to express a choice. A significant body of research, using patient-surrogate pairs and hypothetical vignettes, has documented that surrogates tend to inaccurately predict patient preferences when making these decisions (Shalowitz et al., 2006). This results in treatment decisions that do not match what the patient would have selected. Various factors that may influence surrogates' predictive accuracy have been proposed, but no empirical examination of the relation between such factors and accuracy has yet been conducted. This exploratory study investigated whether certain intrapersonal and interpersonal variables predicted surrogates' accuracy, using patient-surrogate dyads and an online survey methodology employing hypothetical treatment decision vignettes.

One-hundred-and-fifty-four adults over age 45 were recruited from Amazon Mechanical Turk and the West Virginia University faculty and alumni listserv to complete an online survey as the "patient" and indicate the treatment option they would prefer in a variety of treatment decision scenarios. Patients then shared a link to a similar online survey with an adult from their life who would likely serve as their surrogate decision maker and make decisions on their behalf in the event of incapacitation. Therefore, 154 patient-surrogate pairs, or 308 total participants, were recruited. Surrogates completed the decision scenarios using the substituted judgment standard, indicating the treatment preference that they thought the patient would prefer. All participants completed self-report measures of the selected interpersonal and intrapersonal variables. Patients and surrogates were compensated with an Amazon gift card for their participation.

Consistent with prior research, the current study found that surrogates are generally poor predictors of patient preferences when selecting interventions on decision vignettes. In terms of intrapersonal variables, surrogates' accuracy when predicting preferences was positively correlated with levels of empathy and religiosity. Surrogates' levels of trust in the medical profession were also positively correlated with accuracy.

When considering their partners' values, surrogates who reported greater perceived similarity to their patients regarding end-of-life values and who perceived their partners as more reluctant to burden others tended to be more accurate. Pairs who reported high discrepancies in perceived similarity on end-of-life values (e.g., the patient reported low similarity while their surrogate reported high similarity, and vice versa) were those in which surrogates were better predictors of treatment preferences. When these significant correlates were included in a multiple linear regression analysis predicting accuracy, the predictive model was significant $(F(6)=3.03$, $R^{2}=.12, p=.008$ ); however, none of the variables appeared as unique predictors.

Examination of accuracy for individual decision vignettes provided further evidence that surrogate medical decision making varies based on the type of treatment decision that is being made, as the variables predicted accuracy for certain decisions when examined individually. An 
exploratory analysis investigated the predictive role of the variables with respect to surrogates' selection of interventions for patients on the decision vignettes. The variables significantly predicted surrogates' selection of intensive interventions, $F(16)=2.28, R^{2}=.24, p=.006$. Of the predictor variables, the only unique predictor was COVID-19-related anxiety, such that surrogates with greater anxiety about COVID-19 tended to select intensive treatments for patients. Findings from this exploratory study can inform the development of more targeted decision-making interventions to improve surrogates' accuracy. Providers may also attend to certain variables to facilitate surrogates' treatment selection and their ability to execute their decision-making role, particularly during the stressful context of the COVID-19 pandemic. 
Table of Contents

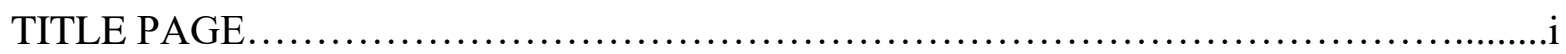

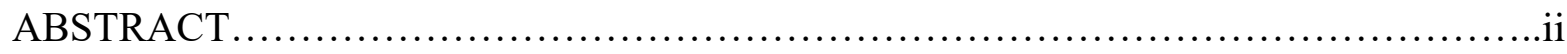

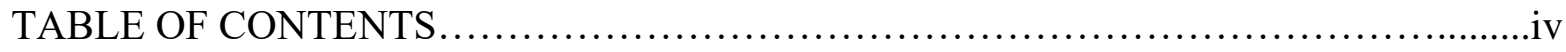

INTRODUCTION ............................................................. 1

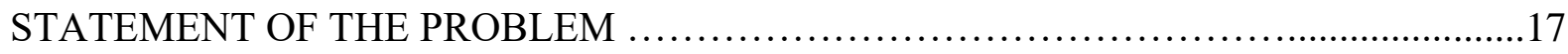

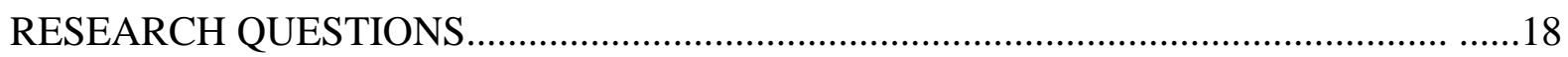

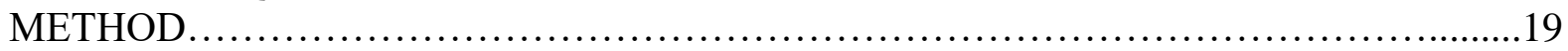

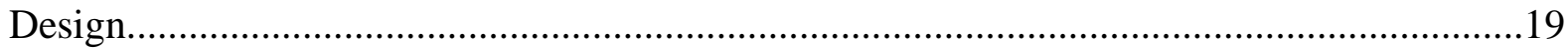

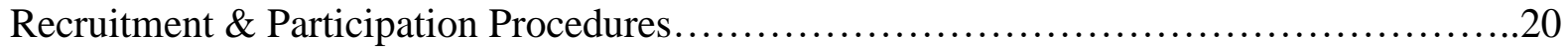

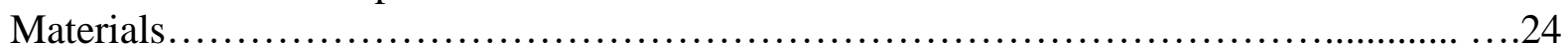

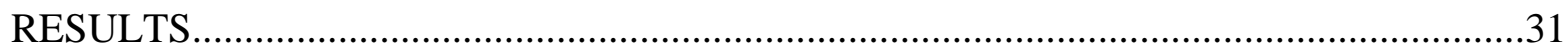

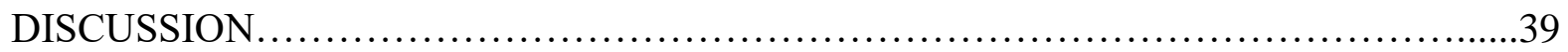

LIMITATIONS \& FUTURE DIRECTIONS ......................................49

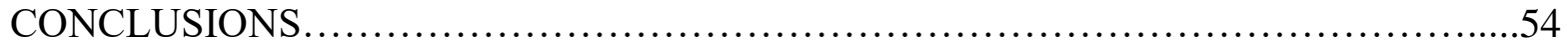

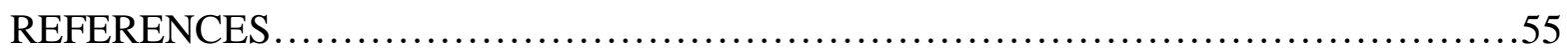

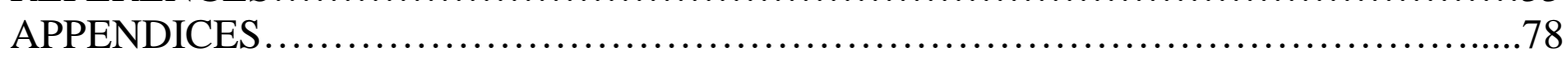

TABLES ........................................................................ 94 
Why Are They Wrong? Exploring surrogates' accuracy when predicting treatment preferences

Decisions about medical treatment at end-of-life are some of the most challenging that a

patient can face. End-of-life care has become a timely topic in the United States, with survey data revealing increased concerns for maintaining personal control over the circumstances of one's death, in addition to greater fears of pain and dependency at end-of-life (Blendon, Szalay, \& Knox, 1992). These issues have also risen in pertinence recently amidst the coronavirus (COVID-19) pandemic, which has brought critical care services and end-of-life care to the forefront of public consciousness (Pattison, 2020). Public health and policy initiatives have also drawn attention to this area as a result of health initiatives stemming from the Patient SelfDetermination Act (Baker, 2002) that promote completion of advance directives outlining endof-life care preferences. Decisions about end-of-life care are unique from other types of medical decisions, since when death is imminent the main goal of treatment may shift from one of quantity to quality, such that providing comfort and reducing pain are prioritized over prolonging life. For instance, in the case of a patient who has lost the ability to breathe independently for an extended period, a decision for the patient may arise regarding whether to be placed on mechanical ventilation or to withhold ventilation and focus on providing comfort care measures for the remainder of his or her life.

\section{Surrogate Decision Making: An Overview}

Decisions about end-of-life medical treatment are often made by individuals other than the patient. This occurs when a patient is unable to express a choice on their own behalf or is otherwise considered incapacitated and no formal documentation (e.g., an advance directive) exists that explicitly states the patient's preferences regarding a particular treatment decision. This situation occurs among nearly half of hospitalized older adults (Torke, Sachs, \& Helft, 
2014) and close to 50\% of all patients considered to be at end-of-life (Tejwani et al., 2013). In these cases, treatment decision making is deferred to the patient's surrogate decision maker (an adult over age 18 hereafter referred to as a "surrogate"). The surrogate is usually a family member or close friend who the patient has identified in advance, most often through a durable power of attorney for medical decisions, which gives written authorization for a specified person to make medical decisions on the patient's behalf.

If such documentation does not exist, or if the person identified is unwilling or unable to serve in the role, decision-making authority for the patient is deferred to another individual based on the state's legal hierarchy. Under this hierarchy, members of the patient's family fall in a priority list of potential surrogates who may be consulted on behalf of the patient. Higher priority rankings are generally given to more immediate family members. In most states, the hierarchy order is as follows: a spouse (unless divorced or legally separated), an adult child, a parent, and an adult sibling (American Bar Association, 2019). The hierarchy list extends to include more distant family members and, in some states, close friends. If the patient has no living family members or close friends who are able to serve (as in the case of an "unbefriended" older adult; Farrell et al., 2017), another non-related individual (e.g., a court-appointed legal guardian) is designated by the patient's treating physician. The chosen surrogate in these situations cannot be the patient's current health care provider or an employee of the patient's primary health care facility. Best-practice guidelines exist, such as those posed in a position statement by the American Geriatrics Society (Farrell et al., 2017), to guide those who are tasked with making medical decisions in these cases.

\section{Surrogate Decision Making and the Issue of Accuracy}


When making medical decisions, surrogates are most often encouraged to use the substituted judgment standard, which specifies that a surrogate should make decisions in accordance with what the patient would have selected if he or she were able to express a choice (Tejwani et al., 2013). Other standards for medical surrogate decision making exist, including the best interest standard, which encourages decision making based on established community norms, and the life narrative approach, which advocates for making decisions within the context of a patient's broader values and life story. The question of whether the decision made by the surrogate agrees with the decision that the patient would have made therefore only emerges in relation to the substituted judgment approach. Subsequently, this approach raises surrogate decision-making accuracy as an issue, regarding whether surrogates adequately predict patient preferences through their decisions. Although criticisms of the substituted judgment standard have been raised regarding its practical utility and the extent to which it can be feasibly executed by surrogates (Bailey, 2002; Torke, Alexander, \& Lantos, 2008), this standard is still considered the most complete option and is currently employed in most states (Tejwani et al., 2013).

Copious research to date suggests that surrogates are often inaccurate when predicting patient preferences. In a systematic review of the surrogate decision-making accuracy literature, Shalowitz (2006) concluded that individuals serving as surrogates predict patient preferences only slightly better than chance, with $68 \%$ accuracy on average. Additional evidence reflects a particularly strong tendency for surrogates to "overtreat" and select a more invasive, lifesustaining treatment than what the patient would want (e.g., Li et al., 2007).

\section{Variables Related to Surrogate Decision-Making Accuracy}

While several studies of surrogate decision-making accuracy and theoretical models (e.g., Marks \& Arkes, 2008; Torke et al., 2008) have proposed factors that may impede surrogate 
accuracy when identifying patient preferences, no research has yet formally investigated the extent to which these factors predict surrogates' accuracy. The variables that have been suggested to date derive from both intrapersonal and interpersonal domains. The following sections describe the variables that have been most frequently proposed to date, as determined by the relative frequency with which they have appeared in empirical and theoretical discussions of surrogate decision-making accuracy. These variables, and others, were subsequently investigated by the current study, which was exploratory in nature and broad in scope.

\section{Surrogate Intrapersonal Variables}

Emotions and Decision Making. The interplay between emotions and decision making has been the subject of considerable empirical attention, with evidence indicating that strong emotions can affect cognitive processes (Forgas 1995), including the manner in which one estimates value (Pham, 2007) and risk (Loewenstein, Weber, \& Welch, 2001). Experiencing strong emotions also appears to increase one's reliance on mood-related cues as a source of information in the moment of decision making (Schwarz \& Clore, 1996). Evidence from neuroscience research involving patients with lesions to the ventromedial cortex, the area of the brain responsible for interpreting emotion-related signals, also supports the notion that information processing operates on an emotional level that plays a considerable role in decision making (Bechara, 2004). Behavioral economics investigations of the "risk-as-feelings" hypothesis, which posits the importance of affect in decision making, shows that emotional reactions to risky situations, such as anxiety, can ultimately drive decision-making behavior by disrupting one's ability to more logically assess risks (Loewenstein et al., 2001). Specifically, the uncertainty surrounding risky situations can stimulate informational processing biases related to 
threat, which prompt risk-averse decision-making tendencies that seek to maximize safety and certainty (Kahneman \& Tversky, 1984; Maner et al., 2007).

The experience of negative emotions may also affect one's preferred role when making decisions. Interestingly, one's decisional style, or preferences for personal involvement when making decisions, appears stable. That is, individuals' preferences do not appear to vary significantly if they experience increases in negative emotions like depression or anxiety (Petersen, Sherman-Slate, \& Straub, 2003). However, among patients (Brown et al., 2002) and relatives (Anderson et al., 2009) who are asked to make medical decisions on behalf of themselves or a loved one, those who meet clinical criteria for anxiety or depressive disorders tend to prefer more passive decision-making roles.

Anxiety and Decision Making. A preponderance of evidence across fields, including theoretical and empirical endeavors, suggest that experiencing anxiety can significantly alter one's decision-making performance (Hartley \& Phelps, 2012). For instance, neuroscience research (Somerville et al., 2004; Wager et al., 2008) indicates that higher trait-level anxiety and clinically significant anxiety symptoms are associated with increased amygdala activation and decreased engagement of areas of the prefrontal cortex that are responsible for logically appraising risks and benefits. These patterns of neural activation can reduce one's ability to comprehend information relevant to a decision-making situation and produce attentional biases that focus attention on negative choice options (Cisler \& Koster, 2010). Increased anxiety can therefore manifest behaviorally as a greater tendency to avoid negative outcomes, regardless of the magnitude of potential gains, when making decisions (Hartley \& Phelps, 2012).

Depression and Decision Making. Similar to anxiety, depression is a psychological factor that has received considerable attention with regard to its influence on decision-making 
abilities (Paulus \& Angela, 2012). Research (Murphy et al., 2001) indicates associations between clinically significant depressive symptoms and impairments in cognitive function, specifically executive functioning abilities involved in decision-making processes. This evidence has raised questions in the field of decision-making capacity as to whether the executive functioning abilities of clinically depressed individuals could be impaired enough to warrant concerns of incapacitation. According to a recent systematic review, current evidence indicates that severe depressive symptoms can impair decision-making capacity, particularly by impeding the extent to which one appreciates the importance of decision-relevant information (Hindmarch, Hotopf, \& Owen, 2013). Moreover, as Grisso and Appelbaum (1995) summarize in a review of the literature, depressive symptoms reduce one's abilities to comprehend information in general, which can produce less-informed and lower-quality decisions.

Anxiety, Depression, and Surrogate Medical Decision Making. The role of emotions in decision making is particularly important to consider in medical contexts. Medical decisions are associated with a high degree of perceived uncertainty, as reported both by providers when engaging in clinical decision making (Beresford, 1991) and by patients themselves when making personal treatment choices (Curley, Eraker, \& Yates, 1984). The considerable pressures of risk and uncertainty when making medical treatment decisions can render patients more susceptible to the influence of their emotions (Kaplan \& Frosch, 2005). For instance, cancer treatment decisions have been conceptualized as requiring patients to manage fears across multiple domains, including treatment side effects, the experience of the disease itself, and the burden placed on potential caretakers and loved ones (Ellis \& Ferrer, 2018; Ferrer, Green, \& Barrett, 2015). Several models of medical decision making have therefore evolved to account for the influence of emotions (e.g., Leventhal \& Patrick-Miller, 1993; Schneider \& Schneider, 1998). In 
particular, Power, Swartzman, and Robinson's (2010) cognitive-emotional decision-making model conceptualizes the act of making a medical decision as a coping mechanism for patients to manage the negative emotions associated with confronting potential threats to their health. In accordance with this model, a patient may be motivated to make a medical decision to eliminate the anxiety and uncertainty preceding the decision, as they consider potential treatment options and prognoses. As a result, Power and colleagues (2010) suggest that patients may be apt to make hasty decisions with minimal consideration as a means of improving their emotional experience more quickly.

These findings from the patient medical decision-making literature can inform research on surrogate decision making, as negative emotions can impair surrogates' abilities to understand and remember detailed, complex medical information pertaining to the patient (Engel et al., 2009). Qualitative and quantitative examinations of the surrogate decision-making experience reveal that the experience of serving as a surrogate can evoke negative emotions, such as posttraumatic stress symptoms (Azoulay et al., 2005) and greater overall self-reported stress, anxiety, and depressive symptoms (Wendler \& Rid, 2011) following instances of treatment decision making.

For surrogates, the experience of making high-stakes medical decisions regarding lifesustaining treatment on behalf of a significant other can provoke anxiety (Powell, 1999). Family members who serve as surrogates appear at risk for suffering from clinically significant anxiety symptoms following their service (Pochard et al., 2001). In a decision-making situation, significant anxiety surrounding the potential ramifications or consequences can impede surrogates' abilities to adequately weigh risks, benefits, and the patient's own values (Ganzini et al., 1994), thereby undermining the extent to which they can accurately predict patient 
preferences (Rid \& Wendler, 2010). Furthermore, service as surrogate requires confronting distressing issues of mortality and end-of-life, which can stimulate feelings of depression and sadness (Pochard et al., 2001). Among surrogates, depressive symptoms are associated with a tendency to overestimate risks and underestimate benefits associated with treatment choices (Ganzini et al., 1994). Therefore, surrogates who are experiencing negative emotions, particularly anxiety or depressive symptoms, may make biased decisions that are less likely to align with patients' treatment preferences, as proposed by Pochard et al. (2001).

Willingness to Assume Responsibility for Decisions. Despite the tendency for patients to report a relatively strong desire for information about treatment options, the extent to which patients take primary responsibility for decisions about personal medical treatment can vary considerably (Charles et al., 1997; Say, Murtagh, \& Thompson, 2006). Patients who prefer more "active" roles in treatment decision making tend to be those who also place greater value on their health (Bishop \& Yardley, 2004); however, being an "active" participant, such as by assuming personal responsibility for a medical decision or engaging in shared decision making, is notably distinct from simply being informed about one's health and treatment options. In fact, evidence suggests that even patients who express a strong desire for personally relevant medical information may not necessarily desire active participation in decisions regarding their treatment, instead preferring to defer these decisions to their providers (Vick \& Scott, 1998).

When making a decision on behalf of oneself or for another person, decision-making behaviors, including one's desire to assume personal responsibility for a decision, often depend on the extent to which this decision could impact others (e.g., Lu, Xie, \& Xu, 2013; Stone \& Allgaier, 2008). For instance, findings from the behavioral economics literature indicate that individuals are generally more loss-averse and more likely to select a less-risky alternative when 
making decisions on behalf of other people (Polman, 2012). In light of such self-other decisionmaking investigations, researchers (e.g., Tilden et al., 1999) have proposed that one's willingness to take responsibility for a decision may vary based on the extent to which the decision involves another person. Investigations with healthcare providers have examined the degree to which providers, particularly those who are still in training phases of their careers or who work as members of interdisciplinary teams, are willing to take full responsibility for hypothetical decisions regarding medication and treatment recommendations (e.g., Cope, Tully, \& Hall, 2019; Maddox et al., 2016). Factors such as self-efficacy (Cope et al., 2019), perceived role and level of authority (Maddox et al., 2016), and perceived risk associated with the decision (Maddox et al., 2016) appear associated with providers' willingness to assume responsibility.

When making treatment decisions on behalf of patients, surrogates often perceive a great deal of personal responsibility associated with their role (Tilden et al., 1999). Surrogates may be uncomfortable with this sense of obligation, particularly when making medical decisions that they perceive as requiring technical medical knowledge. Johnson and colleagues (2011) employed an example of a "technical" medical decision in their investigation of how surrogates' desires to take responsibility for a decision varied across different types of decisions. They found that surrogates preferred to retain more responsibility for decisions they viewed as more "value-based," such as the decision of whether to keep a patient on life support, than for those they viewed as more technical, such as the choice of which antibiotic to use to treat an infection. While it is important to consider how surrogates may respond differently to various types of decisions, the practical implications of these findings are minimal given that surrogates in real clinical settings are more likely to be consulted regarding "value-based" decisions (Tejwani et al., 2013). 
Value-based end-of-life decision research (e.g., Mezey et al., 1996; Uhlmann et al., 1988) indicates that surrogates tend to choose treatment options with fewer associated risks or potential negative consequences. Importantly, they tend to make these decisions regardless of whether these choices align with patient preferences, which results in poor agreement. In a review of this literature, Shalowitz and colleagues (2006) interpreted these findings as reflecting surrogates' desires to minimize their sense of personal responsibility regarding such high-stakes decisions, in a sense "deferring" potential liability for a negative outcome. Examining surrogates' willingness to assume responsibility for their decisions has important implications for more broadly understanding and improving surrogate decision making. For instance, surrogates who express greater willingness to take responsibility for their decisions are more likely to be willing to engage in positive decision-making behaviors that could foster patient-surrogate agreement, such as collaborating with the patient's physician (Spalding \& Edelstein, 2020).

\section{Understanding Costs and Benefits of Treatment Options. Improving patient} understanding of treatment options, including details of potential risks, side effects, and outcomes, is central to the prevailing model of shared decision making currently advocated by the United States healthcare system (Kon et al., 2016). Prior research indicates that surrogates who feel more well-informed regarding treatment options and the patient's condition report greater confidence in their decision making (Vig et al., 2007), which may promote the extent to which they are able to attend to patient preferences.

Empathy. Davis' multidimensional model of empathy is most commonly used in the literature pertaining to self-other decision making and includes components of perspective taking and empathic concern, or the ability to feel concern for others (cf. Davis, 1980). Both perspective taking and empathic concern have been raised as central theoretical components of surrogate 
decision making under the substituted judgment standard (e.g., Tunney \& Zeigler, 2015a). In an examination of which components of Davis' model of empathy were most strongly related to decision making on behalf of others, Tunney and Zeigler (2015b) found that empathic concern particularly predicted individual abilities to make judgments that more closely aligned with the views of another person, rather than with their own preferences. Further evidence indicates relations between individual differences in empathy and accuracy when making decisions on behalf of others; for instance, Faro and Rottenstreich (2006) found support for an "empathy gap" (Loewenstein, 2005) such that individuals with greater self-reported empathy were able to more accurately predict others' preferences in risky choice vignettes. Empathy may also affect accuracy in the specific self-other decision-making situation of surrogate decision-making. Qualitative explorations of the surrogate decision-making process support the role of empathy in these contexts, as surrogates frequently identify empathy for the patient as influencing their decision-making process (Meeker, 2004).

Religiosity and religious preference. Religiosity, or the extent to which one engages in private and public religious practices, has yet to be formally examined in relation to surrogate decision-making accuracy. Prior investigations (Coppolino \& Ackerson, 2001) have found religious affiliation to be unrelated to accuracy. That is, accuracy does not seem to vary across members of specific religious groups. However, one's particular commitment to religion and beliefs surrounding the afterlife undoubtedly have bearing on one's conceptualizations of end-oflife and preferences for care, as documented by research among patients and family surrogates (Steinhauser et al., 2000). Therefore, by extension, religiosity could shape accuracy. No research to date has examined relations between religious preferences and accuracy. 
Gender. Investigations of medical surrogate decision-making accuracy between marital partners evidences gender differences, as wives tend to be more accurate than their husbands in hypothetical surrogate decision-making tasks (Zettel-Watson et al., 2005).

Education. Education level is associated with health literacy and health outcomes more broadly, such that health literacy mediates the association between low education and poorer health (Van der Heide et al., 2013).

Ethnicity. In the United States, ethnic disparities in health outcomes and access to healthcare resources are well-documented. Individuals of minority backgrounds generally report poorer health, reduced health care utilization, and more frequent encounters with providerpatient discrimination (Lee, Ayers, \& Kronenfeld, 2009), all of which are variables that can have considerable bearing on end-of-life decision making.

Age. Finally, given research suggesting that preferences and beliefs surrounding lifesustaining treatment may vary across age groups (Phillips et al., 1996), age may also be related to surrogates' accuracy.

\section{Surrogate Interpersonal Variables}

Reluctance to Burden Others. Perceived burdensomeness, or the extent to which one feels like a burden on other people, is a construct that has been heavily investigated in relation to suicidality (Joiner et al., 2002; Van Orden et al., 2006) and depressive symptoms (Jahn et al., 2011). However, concerns for excessively burdening significant others and potential caregivers can occur under a variety of conditions. Such concerns appear prevalent among patients with chronic pain (Kanzler et al., 2012), cancer (Simmons, 2007) and other critical illnesses (Zweibel \& Cassel, 1989), healthy adults (Tomlinson et al., 1990), and older adults (Cahill et al., 2009; Kogan \& Edelstein, 2004). Across the lifespan, fears of burdening loved ones appear most 
salient among younger adults and older adults, with relatively less concern of burdensomeness reported at mid-life (Bausewein et al., 2013). These concerns can have an impact on individuals' healthcare behaviors, such as when interacting with providers or participating in medical decision making. For instance, cancer patients report that a main barrier that inhibits the frequency with which they ask questions of their providers is their reluctance to burden the physician (Maguire et al., 1996).

Winter and Parks (2012) investigated how reluctance to burden others (RBO) may manifest in patient-surrogate relationships by asking pairs the extent to which they felt that RBO affected their medical decisions, in general. When reporting on this variable, surrogates were instructed to use the substituted judgment standard and provide an estimate of how much they thought the patient considered RBO as relevant to their medical decisions. Findings indicated that pairs with greater differences in RBO (e.g., pairs in which the patient rated that they were much more concerned with burdening others than the surrogate had estimated, or vice versa) were more likely to be those in which surrogates inaccurately predicted patient treatment preferences. Therefore, surrogates' inaccurate estimates of the patient's RBO may predict their accuracy when reporting the patient's wishes.

Perceived Similarity between Self and Patient. In interpersonal relationships, perceiving similarities between oneself and another person is beneficial for fostering feelings of kinship and intimacy (Murray, 1999). This occurs when one perceives another person as ascribing to one's own beliefs, regardless of whether any explicit evidence has been given to support this belief. For instance, research among pairs of well-acquainted adults shows a particular tendency for individuals to project their own moral values onto others and view other people as ascribing to their views (Cohen et al., 2013). Decisions about end-of-life treatment in 
particular may tap moral considerations associated with personal values surrounding death and quality of life (Pellegrino, 2000). In proxy decision-making contexts in which one individual (the "proxy") is making choices on behalf of another person (the "patient"), proxies who assume that patients share their personal values may be more accurate when predicting patients' preferences, if the proxy and patient hold similar beliefs (e.g., Cronbach, 1955). This follows under the valuebased conceptualization of medical treatment preferences as informed in part by one's personal beliefs (e.g., prioritizing quality of life over quantity; Winter, 2013).

However, if the values, and associated treatment preferences of the patient are in fact dissimilar to those of the proxy, this assumption can undermine the proxy's accuracy when predicting patient preferences. This is particularly problematic in light of evidence indicating that perceived similarity is quite high among pairs of close relatives who would likely serve as each other's surrogates, particularly among spouses (McDade-Montez, Watson, \& Beer, 2013). In a surrogate decision-making situation, surrogates may struggle to disconnect their own values from those of the patient (Fagerlin et al., 2002), despite being instructed to use the substituted judgment standard and make decisions that best reflect patients' beliefs. This bias towards one's own personal values can reduce surrogates' accuracy when attempting to predict medical treatment preferences, as these preferences are often substantially informed by personal values (e.g., Pruchno et al., 2005; Vig et al., 2007).

Perceived Emotional Support. Providing emotional support involves communicating support, sympathy, and compassion for another person (Cohen \& Wills, 1985). Emotionally supportive messages can comfort individuals undergoing stress because such messaging conveys another's care and concern, regardless of the outcome of a situation (Weber \& Patterson, 1991). Research in intensive care settings, where patients and their family members often face stressful 
medical decisions, indicate that emotional factors play an essential role in facilitating decision making, particularly for surrogates (e.g., Nelson et al., 2006). Specifically, intervention implementation studies with family members and surrogates reveal that interventions with an emotional support component, in which a provider explicitly provides comfort or acknowledges the surrogate's present emotional difficulties, improve surrogates' confidence in their own ability to articulate patients' values and communicate effectively with providers (e.g., White et al., 2012; Gay et al., 2009). Furthermore, studies of provider behaviors during treatment decisionmaking interactions with surrogates indicate that providers' activities that seek to provide emotional support, such as expressing empathy (Selph et al., 2008) and maintaining consistent communication (Pochard et al., 2001) are associated with patients' improved satisfaction and comfort with the decision-making experience. Although emotional support has not yet been examined in relation to surrogate decision-making accuracy, an emotionally supportive environment may enhance surrogates' abilities to consider the decision-making situation and render a decision that matches patients' preferences. Specifically, the extent to which surrogates perceive that they receive emotional support from their patient partner will be evaluated.

Trust in the Medical Profession. Over recent decades, shared decision making has gained traction within the United States healthcare system as a prevailing model of clinical practice (Elwyn et al., 2012; Kaplan, 2004). With this increased attention to promoting a balanced involvement between patient and provider, factors influencing the patient-provider relationship have come into focus. One such factor is patients' degree of trust in the medical profession. Generalized trust in the medical profession has been conceptualized as having five central components: fidelity, competence, honesty, confidentiality, and global trust (a combination of elements from each of the other four components that describes the "soul" of 
trust; Hall et al., 2002). Greater trust in the profession is also associated with better self-reported health and higher satisfaction with care and the medical decision-making process among patients (Armstrong et al., 2006). Moreover, trust in the profession appears strongly related to views regarding personal involvement in medical decision making than trust in specific providers (Hall et al., 2002; Trachtenberg et al., 2005), with greater trust in the profession associated with more accepting views towards shared decision making (Arora \& McHorney, 2000; Blanchard et al., 1988; Trachtenberg et al., 2005).

Low levels of trust in the medical profession may make decision making more difficult for patients and has been purported to reduce the quality of their medical decisions (Torke et al., 2014). The extent to which surrogates' levels of trust affect the decisions they make for patients or their decision-making behaviors has yet to be explored. Feelings of trust towards the profession likely varies among surrogates, as these feelings are informed by individuals' unique prior experiences in the context of the healthcare system, whether through their own healthcare interactions or when serving as a surrogate. Surrogates with a high degree of trust in the medical profession may feel more supported in their decision making and be better equipped to provide more accurate reflections of patient preferences.

\section{Degree of Communication with Partner about End-of-Life Treatment Preferences.}

Similar to how a better understanding of treatment options promotes surrogates' confidence in their decisions, surrogates who have engaged in more communication with patients about their preferred care at end-of-life report that this facilitates their ability to serve in the role (Vig et al., 2007). One could expect that surrogates who report that they have discussed preferred treatments more extensively with patients would be more accurate predictors of their preferences. 
Consideration of COVID-19. Lastly, given the unique circumstances of a global pandemic under which data collection occurred, the potential role of the COVID-19 pandemic was considered. Recent research has found associations between the onset of the current COVID-19 pandemic and worsened mental health outcomes, in terms of increased anxiety and depression symptoms, with these symptoms heightening as the pandemic continued (e.g., Ahmed et al., 2020; Tang et al., 2020). As previously described, anxiety and depression have been found to significantly alter one's performance in medical decision-making contexts (Hartley \& Phelps, 2012; Paulus \& Angela, 2012). Therefore, the extent to which surrogates reported feelings of anxiety or concern regarding the pandemic was included as a predictor variable because it could potentially influence medical decision making.

\section{Statement of the Problem}

Despite consensus among the research community that surrogate decision-making accuracy is a pertinent topic, little to no research to date has investigated what variables predict accuracy. Researchers have suggested that future endeavors need to adopt a more nuanced approach to surrogate decision making, assessing individual variables that may be involved in the process (Berger, 2010; Spalding, 2020; Tunney \& Zeigler, 2015). Efforts to manipulate these variables could improve surrogates' accuracy, if patient-surrogate agreement on decisions is the main objective of surrogate decision making, as it is currently under the favored substituted judgment standard.

The current study sought to replicate the study by Hare et al. (1992) in which they investigated surrogate medical decision-making accuracy. These authors administered five hypothetical treatment decision vignettes to patient-surrogate pairs and investigated the extent to which agreement between pairs occurred. Findings indicated that agreement between patients 
and their surrogates occurred, on average, $70 \%$ of the time. In other words, surrogates predicted patient preferences with an accuracy level worse than chance, as kappa values ranged from .14 .42 across the decision vignettes. The current study also extended this work by investigating the extent to which specific variables can predict accuracy. Variables were grouped into two main categories: intrapersonal characteristics of surrogates themselves (including demographic features of age, race/ethnicity, education level, and type of relationship between patient and surrogate), and interpersonal variables operating between surrogates and other individuals who may be involved in the decision-making process. Furthermore, in light of evidence that surrogates' decision-making preferences and behaviors can vary based on the type of decision being made (Johnson et al., 2011; Spalding \& Edelstein, 2020), this study also investigated whether the variables that predict accuracy differ across the decision vignettes. Given the relative dearth of research in this area, the current study was broad and exploratory in scope. Ultimately, this study aimed to more explicitly identify variables for investigation and manipulation in future research designs and interventions pertaining to surrogate decision-making accuracy.

\section{Research Questions}

1) To what extent are the selected intrapersonal and interpersonal variables related to accuracy?

a. Do the variables predict surrogates' accuracy when attempting to execute the substituted judgment standard on hypothetical surrogate end-of-life treatment decisions?

i. Intrapersonal variables: surrogates' age, education level, self-rated physical health, COVID-19-related anxiety, religiosity, trait-level 
anxiety, depression, empathy, understanding of treatment options, willingness to assume full responsibility for decisions

ii. Interpersonal variables: surrogates' trust in the medical profession, surrogates' perceived emotional support from partner, surrogates' perception of the extent to which the patient is reluctant to burden others, extent to which surrogate has communicated with partner about end-of-life treatment preferences, difference between surrogates' and patients' perceived similarity on end-of-life values, surrogates' perceived similarity to patients on end-of-life values

2) Do the variables that predict accuracy differ based on the type of decision being made?

3) What patient-reported variables predict accuracy?

\section{Method}

\section{Design}

Since assessing surrogates' accuracy relative to real end-of-life treatment decisionmaking situations poses great methodological difficulties, most studies in this literature have employed procedures involving hypothetical decision-making vignettes. In these studies, patients and their designated surrogates (or individuals who would most likely serve in this role) are asked to select the treatment decision they would make for themselves or on behalf of the patient in various vignettes associated with terminal health conditions or end-of-life. For instance, in one representative study, Hare, Pratt, and Nelson (1992) administered five case vignettes to pairs of community outpatients and their designated surrogates regarding preferences for life-sustaining interventions (mechanical ventilation, cardiopulmonary resuscitation, chemotherapy, feeding tube implantation, emergency amputation; see Appendix B). 
The current study followed the dyadic, survey-based methodology of Hare et al. (1992). Similar online survey methodologies have been successfully used in recent dyadic studies, including those with married couples (e.g., Helsper \& Whitty, 2010), parents and children (e.g., Oh et al., 2016), grandparents and grandchildren (e.g., Spalding \& Carpenter, 2018), cancer patients and care partners (e.g., Hamilton et al., 2016), and older adults and their caregivers (e.g., Nahm et al., 2012). To ameliorate a procedural weakness of the original study, an adjustment was made to the manner by which surveys were administered to patient-surrogate pairs. Hare et al. (1992) disseminated surveys to participants via postal mail and offered a substantial response window during which surveys could be returned. Despite being instructed not to discuss the study with others at the time of recruitment, patients and surrogates may have nonetheless discussed patients' end-of-life care preferences prior to returning the surveys, potentially inflating estimates of surrogates' accuracy. In an attempt to discourage patient-surrogate discussion during study participation, participants read and signed an electronic confidentiality statement twice: once upon beginning the online survey, and again at completion.

\section{Recruitment \& Participation Procedures}

All study procedures occurred through an online survey hosted through Qualtrics. "Patient" participants with a healthcare surrogate, or who could identify an individual most likely to serve in this role, were initially recruited through Amazon Mechanical Turk and the West Virginia University (WVU) alumni and faculty listserv (Mountaineer ENews). Since issues related to medical treatment decisions and end-of-life are likely most salient for middle-aged and older adults, a minimum age criterion of 45 years old was used for patients. At the time of participation, patients were provided with a link to an online survey to share with their surrogate partner for them to complete. Once connected to the survey link, both patients and surrogates 
indicated their consent to participate by reading a consent form, provided as Page 1 of the online survey, and proceeded to the next page of the survey. Surrogates were required to be over age 18 , capable of reading English, and to have access to an email account.

Data collection occurred in two stages. In the first stage, approximately May 1, 2020 July 3, 2020, pairs of surrogates and patients were recruited through MTurk. During the first stage, both patients and surrogates were compensated $\$ 1$ for their participation over MTurk or through an Amazon gift card sent to an email account. However, after the participation advertisement had been posted on MTurk for about two months, the pool for eligible and interested participants appeared to have been exhausted. At this point, the WVU alumni and faculty listserv (ENews) was used as an alternate recruitment source in the second stage of the study, approximately July 15, 2020 - August 1, 2020. To further incentivize recruitment, compensation for participation was also increased to a \$2 Amazon gift card, dispersed to one’s email account, for both patient and surrogate at this time. In an effort to discourage missing data, or cases in which only one member of a dyad completed the survey, pairs in which both patient and surrogate respond were entered into a drawing for a \$100 Amazon gift card. Participants were informed of compensation and the potential to be selected through the raffle drawing at the time of consent.

First, all participants completed a demographic questionnaire (see Appendix A). As part of this questionnaire, participants also provided the email address of the individual who would be participating as their "partner" (either as the corresponding patient or surrogate) in the study. At this time, participants read and signed an electronic confidentiality statement indicating their pledge to not discuss the contents of this survey with their partner. The confidentiality statement included an explanation of why such non-disclosure was necessary. 
Following the demographic questionnaire, participants completed the online survey. Two versions of the online survey were created: a surrogate version and a patient version. The versions differed based on the language used in the hypothetical medical decision vignettes. The first portion of the survey consisted of hypothetical medical decision vignettes, including those designed by Hare et al. (1992; see Appendix B). Surrogates were instructed to complete the decisions using the substituted judgment standard on behalf of the patient. Patients were instructed to complete the decisions to indicate their own preferences.

Next, all participants completed self-report measures corresponding to each of the predictor variables (see Appendices C-J). To control for order effects, the order in which participants completed these measures was randomized. In the final stage of the survey, participants again read and signed an electronic confidentiality statement indicating that they did not discuss contents of the survey with their partner.

Validity Check Items. Several validity check measures were incorporated to promote the collection of high-quality data. First, to check for valid age reporting, participants were asked to report their age and birth year at the beginning of the survey and at its conclusion. Responses with discrepancies of greater than 1 year were discarded. Second, each of the self-report measures included one validity check item (e.g., "Please select "very much so" for this item.") to check for participants' attention to the study materials. Responses reflecting more than one incorrect attention check response were not included in analyses. Third, for each version of the survey, responses that omitted more than $25 \%$ of the survey items, or those that omitted an entire measure, were discarded.

\section{Participants}


One-hundred-and-sixty-one pairs, or 322 total participants, were recruited. Patients were recruited first through advertisements posted on MTurk and ENews. At the time of their participation, patients were asked to identify an individual from their lives who would likely serve as their surrogate and who could participate as their "partner" in the study. Then, they referred this person to the study using a provided survey link. One-hundred-and-one pairs were recruited through ENews, whereas 60 pairs responded through MTurk.

Of the 161 total pairs recruited, seven pairs were excluded from subsequent analyses: three pairs due to the surrogate's omission of a substantial portion of the survey, three due to the patient's omission of a substantial portion of the survey, and one due to the surrogate responding incorrectly to more than one attention check item. Therefore, a final sample of 154 patientsurrogate pairs remained.

\section{Surrogate Characteristics.}

Surrogate participants ranged in age from 22 to 88 years old $(M=47.38$ years; $S D=$ 9.98) and reported an average of 15 years of education $(S D=4.32)$. Surrogates recruited via ENews were slightly older than those recruited via MTurk, with a mean age of 48.65 and 45.38 , respectively. Over three-quarters of surrogates identified as Christian (57.8\%) or Roman Catholic (18.8\%). All surrogates resided in the United States, with $20.8 \%$ reporting residence in the Midwest, $29.9 \%$ in the Northeast, $9.1 \%$ in the Northwest, $26.9 \%$ in the Southeast, and $11.9 \%$ in the Southwest. The majority of surrogates identified as female, married, and White/Caucasian (see Table 1). In terms of reported relation to their patient partner, most $(83.8 \%)$ of the surrogates were spouses or romantic partners, $7.1 \%$ were parents, $3.9 \%$ were siblings, $3.9 \%$ were close friends, and $.6 \%$ were adult children or another family member. Surrogates reported relative familiarity with the role of serving as a surrogate, with $77.9 \%$ indicating that they had 
served as a surrogate in a formal capacity (per the request of a physician) and $76.6 \%$ reporting informal service. Only 2 surrogates indicated that they did not have health insurance and most reported generally good self-rated physical health on a scale of " $1=$ poor" to " $5=$ excellent," $M$ $=3.63, S D=.840$.

\section{Patient Characteristics.}

Patient participants ranged in age from 45 to 71 years old $(M=51.24, S D=5.52)$ and reported 15.5 years of education $(S D=4.66)$, on average. No significant demographic differences were observed between those recruited via MTurk versus ENews. One patient indicated that they did not have health insurance. Similar to the surrogate sample, over threequarters of patients identified as Christian (58.4\%) or Roman Catholic (14\%). The majority of patients identified as male, married, and White/Caucasian (see Table 2). All patients reported residing in the United States, with $21.6 \%$ identifying residence in the Midwest, $30.1 \%$ in the Northeast, $10.7 \%$ in the Northwest, $22.9 \%$ in the Southeast, and $15.0 \%$ in the Southwest. Patients rated their physical health as "good," on average $(M=3.55, S D=.85)$.

\section{Materials}

\section{Criterion Variable Measure}

Choice of End-of-Life Medical Treatment. As a replication of Hare et al. (1992), the current study employed the same five medical treatment decision vignettes used in this study, in addition to two decision vignettes commonly considered in advance directive end-of-life treatment preference documentation (White \& Arnold, 2011; see Appendix B). The vignettes asked respondents to choose whether to administer a treatment in situations concerning the following: ventilation, resuscitation, tube feeding, chemotherapy, amputation, bypass surgery, and dialysis treatment for chronic kidney disease. Surrogates were instructed to make decisions 
using the substituted judgment standard and make the decision they thought the patient would make. Patients made decisions on the vignettes as self-report, indicating the treatment that they would want to be provided. Wording in the vignettes was identical for both patient and surrogate versions, except for minor changes to indicate that the respondent was the patient. In response to each vignette, respondents selected either to accept (scored as " 1 ") or decline (scored as " 0 ") the treatment that is explained and offered in the vignette. Scores were summed across the vignettes to create a total treatment selection score, with higher scores indicating a stronger tendency to accept presented treatment interventions. This "intervention preference" score was used in subsequent analyses. To operationalize surrogates' accuracy, patient-surrogate agreement scores were calculated for each pair using a similar method to that used by Hare et al. (1992). Vignettes on which the pair agreed were scored as 1 and summed. Therefore, agreement scores for each pair ranged from 0 to 7 , with higher scores denoting higher agreement, or greater accuracy by the surrogate.

\section{Predictor Variable Measures}

In the primary regression analysis evaluating the prediction of surrogates' accuracy when making treatment decisions, surrogates' self-reports were used as predictor variables. Note, however, that both patients and surrogates completed these measures.

In relation to the treatment decisions, participants were also asked to rate, on a 5-point Likert-type scale, the extent to which they felt they understood the costs and benefits associated with the treatment that was being offered for each decision. Scores were summed across the seven vignettes to obtain a total "treatment understanding" score ranging from 7 to 35 . Higher scores reflected greater self-assessed understanding. Surrogates also responded to a single item indicating the extent to which they had talked with their partner about end-of-life care 
preferences, using a 4-point scale, where " $1=$ not at all," " $2=$ a little," " $3=$ moderately," and "4=very much."

COVID-19. As part of the demographics questionnaire to assess respondents' current experience of the pandemic, each participant rated the following statement on a 10-point scale, with ratings ranging from " $1=$ not at all" to " $10=$ very much so," in response to the following question: "How worried are you about the COVID-19 pandemic?"

Trust in the Medical Profession. The extent to which participants trusted the medical profession in general was assessed by the 11-item scale developed by Hall and colleagues (TIMPS; Hall et al., 2002). Respondents used a five-point Likert scale ranging from 1 (strongly disagree) to 5 (strongly agree) to rate the extent to which they trust the medical profession in general (e.g., "Doctors are extremely thorough and careful."). The measure has been widely used in investigations of patients' trust in the medical profession (e.g., Klest \& Philippon, 2016; Thom et al., 2004) and demonstrates good psychometric properties, with high internal consistency reliability ( $\alpha=.89$; Hall et al., 2002) among nationally representative community-dwelling samples. Convergent validity evidence was provided for this measure through demonstrated positive relations with measures of satisfaction with care, trust in one's physician, and willingness to follow physician recommendations (Hall et al., 2002).

Perceived Emotional Support. The Communication Based Emotion Support Scale (CBESS; Weber \& Patterson, 1996) assessed the degree to which participants perceive that they receive emotionally supportive messages from their partner in this study. This 13 -item, unidimensional self-report measure uses a five-point Likert-type scale ranging from 1 (almost never true) to 5 (almost always true). Although this measure was originally developed for use with romantic partners, it has been successfully modified with slight wording changes for use 
when assessing views of emotional support given by friends and significant others (e.g., Rittenour \& Martin, 2008). Both the original version of the scale and modified versions demonstrate strong psychometric properties, with good internal consistency reliability reported for the original scale ( $\alpha=.83-.90$, Avtgis, 2003; Weber, Johnson, \& Corrigan, 2004) and the modified version ( $\alpha=.93$; Rittenour $\&$ Martin, 2008). Convergent validity evidence for this measure exists through demonstrated positive associations between scores on this measure and self-reported relationship quality (Weber \& Patterson, 1996), multidimensional perceived social support, and engagement in social support behaviors with significant others (Rittenour \& Martin, 2008). Since the current study was interested in measuring respondents' feelings of emotional support regarding their partner in this study, slight wording modifications were made to the original measure (e.g., substituting “your partner in this study” for "romantic partner”).

Perceived Similarity between Self and Patient. To assess surrogates' perceived similarity to patients regarding values specifically related to end-of-life treatment, the Quality of Life Values Inventory (QLVI; Cohen-Mansfield, Droge, \& Billig, 1992) was used. Respondents used a five-point Likert scale ranging from 1 (strongly disagree) to 5 (strongly agree) to indicate their level of agreement with five statements reflecting the relative importance they place on quality of life, prolonging life, and placing burden on others (e.g., "I'd rather not live than be a burden on others.”). The QLVI demonstrates adequate internal consistency reliability among community-dwelling samples ( $\alpha=.61$ - .67; Cohen-Mansfield et al., 1992; Cicirelli, 1997). Convergent validity evidence for this values measure exists in its demonstrated relations to endof-life treatment preferences, the number of additional years respondents desired to live, and measures of multidimensional locus of control (Cicirelli, 1997; Cohen-Mansfield et al., 1992). 
As an additional measure of values related to quality of life at end-of-life, the 13 -item Life Values measure designed by Schonwetter and colleagues (LVI; 1996) was used. Created as a modification of Doukas \& McCullough's (1991) Values History, the measure asks respondents to use a five-point Likert-type scale ranging from 1 ("not at all true for me") to 5 ("very true for me") in response to a series of statements regarding values related to end-of-life.

To assess perceived similarity, participants rated each of the 18 items from both of these measures using a five-point Likert-type scale ranging from 1 (exactly the opposite of me) to 5 (exactly the same as me) to reflect the extent to which they thought their partner's values regarding the item were similar to their own. Ratings on the items were summed to produce a total perceived similarity score ranging from 18 to 90 .

Empathy. The extent to which participants possessed empathy, or concern for others, was measured by Davis' (1980) 28-item Interpersonal Reactivity Index (IRI), scored on a 5-point Likert-type scale with possible scores ranging from 28 to 140. The IRI measures empathy across four subscales including perspective taking, fantasy, empathic concern, and personal distress. Satisfactory internal consistency reliability has been demonstrated for this measure $(\alpha=.71$ .77; Davis, 1980).

Willingness to Assume Full Responsibility for Medical Decisions. The extent to which participants were willing to take full personal responsibility for medical decisions was assessed using the behavioral involvement subscale of the Health Opinion Survey (HOS; Krantz, Baum, \& Wideman, 1980). This subscale consists of nine items focusing on the respondent's desire to participate in self-management of their medical treatment and care (e.g., "It's almost always better to seek professional help than to try to treat yourself."). For each item, respondents indicated either 0 (disagree) or 1 (agree); therefore, scores on this measure ranged from 0 to 9 , 
with higher scores indicating favorable attitudes towards self-directed decisions about medical treatment. Possible scores therefore ranged from 0 to 81 . According to a review of measures of patient preferences for shared decision making (Chewning et al., 2012), the behavioral involvement scale demonstrates good internal consistency reliability (KR-20 = .74 - .75). Good test-retest reliability for the subscale has also been reported ( $\alpha=.71$; Krantz et al., 1980). Convergent validity evidence for the subscale has been demonstrated through positive relations between scores on the subscale and behavioral measures of engagement in self-management of health care (e.g., those who score higher on the subscale tend to be those who attempt to treat themselves first before presenting for treatment in a medical clinic; Krantz et al., 1980).

Anxiety. The State-Trait Anxiety Scale, Trait Subscale (STAI-T; Spielberger, 1983) assessed trait-level anxiety. The STAI-T is a 20-item instrument that measures the respondent's tendency to experience anxiety and perceive situations as threatening. Respondents indicated the degree to which each statement is true of themselves, in general, on a Likert-type scale ranging from 1 (not at all) to 4 (very much so). Possible scores ranged from 20 to 80, with higher scores indicating greater levels of trait-level anxiety. The measure has high test-retest reliability, ranging from $.73-86$. Strong concurrent validity evidence with other measures of anxiety has been reported, ranging from .73-.85 (Spielberger, 1983).

Depression. The Center for Epidemiological Studies Depression Scale-Revised (CESDR; Eaton et al., 2004) assessed depressive symptoms. The measure is an updated version of the CES-D (Radloff, 1977) and consists of 20 items reflecting depressive symptoms consistent with DSM-V criteria for depression. Respondents indicated the frequency with which they have experienced each symptom over the past 2 weeks using a scale ranging from 1 (not at all or less than 1 day) to 5 (nearly every day for the past 2 weeks). The measure is scored on a scale of $0-$ 
3, with responses indicating a frequency of 4 (5-7 days) or 5 (nearly every day) both receiving a score of 3 . Total scores on the measure therefore ranged from 0 to 60 , with higher scores indicating greater depressive symptoms. The measure demonstrates good psychometric properties, with high internal consistency reliability among community-dwelling samples $(\alpha=-$ .93, Van dam \& Earleywine, 2011) and good convergent validity with measures of theoretically associated constructs, such as negative affect (Van dam \& Earleywine, 2011).

Reluctance to Burden Others. This exploratory variable was assessed using the measure developed by Winter and Parks (RBO; Winter \& Parks, 2012). Three items reflected three components of perceived burdensomeness through the following questions: "To what extent do you feel it is important to avoid burdening your family and friends emotionally as a result of your medical treatment decisions?", "To what extent do you feel it is important to avoid burdening your family and friends financially as a result of your medical treatment decisions?”, "To what extent do you feel it is important to avoid being dependent on others as a result of your medical treatment decisions?". Surrogates were instructed to respond to these items using the substituted judgment standard. Therefore, they provided the response they thought the patient would choose on a Likert-type scale ranging from 1 (not at all important) to 5 (very important). Ratings on the items were summed to produce a total RBO score ranging from 5 to 15 . Patients completed this measure as a self-report. Differences between patients' self-reported reluctance to burden others and surrogates' proxy reports were also computed to examine relative to surrogates' accuracy, in an attempt to replicate findings from Winter and Parks (2012).

Religiosity. This construct was assessed by the Duke University Religion Index (DUREL). The DUREL measures religiosity through five self-report items (Koenig \& Bussing, 2010). The first three items ask respondents to indicate the frequency with which they participate 
in certain religious activities, using a 6-point scale ranging from " $1=$ never" to " $6=$ more than once a day." The final items measure intrinsic religiosity, such as experiencing the presence of a higher power, on a 6-point scale ranging from " $1=$ definitely not true of me" to " $6=$ definitely true of me." Total scores therefore ranged from 6 to 30, with higher scores indicative of greater religiosity. The measure demonstrates adequate internal consistency reliability $(\alpha=.78-.91)$ and convergent validity evidence through strong correlations with other religiosity measures $(r=.71$ .86; Koenig \& Bussing, 2010).

\section{Results}

\section{Handling of Missing Data}

Missing values analyses verified that patterns of missingness occurring in the data were consistent with missingness patterns completely at random or at random. An expectation maximization procedure was then used to account for problematic missingness in measures (greater than 5\% of items; Field, 2013). Values imputed via expectation maximization were used for the CESD-R, the QLVI and LVI, the IRI, the TIMPS, and the STAI.

Of note, data collection was attempted for two additional variables: social norms pertaining to treatment options, and the extent to which participants felt confident that the decisions they made on treatment vignettes were consistent with what the patient would have wanted. However, unforeseen patterns of missingness arose for these variables, and greater than $30 \%$ of surrogates failed to complete these items. When the regression analysis was conducted across all vignettes with the smaller sample of participants who completed these items (108 surrogates), the predictive model was still not significant. Therefore, these variables were determined to not contribute any additional information and were excluded from further 
analyses. Correlations between these variables and major outcome variables (agreement scores and intervention selection) are available in Appendix K.

\section{Organization of Results}

First, descriptive results pertaining to the intrapersonal and interpersonal variables are presented. Means and standard deviations for these variables, as reported by surrogates, appear in Table 5. Next, since two recruitment methods (WVU ENews and MTurk) were used, results of analyses comparing samples from the two recruitment sources are provided. The section concludes by presenting results pertaining to each of the main research questions.

\section{Intrapersonal variables}

Surrogates reported moderately high levels of empathy on the IRI. The IRI demonstrated good internal consistency reliability $(\alpha=.77)$ for the current sample. As measured by the HOS, surrogates demonstrated a tendency to view treatment decision-making autonomy as appropriately placed in the hands of the physician, (skew $=-.871)$. Adequate internal consistency reliability was evident, $\alpha=.68$.

In general, surrogates reported moderate levels of religiosity. Internal consistency reliability on the DUREL was excellent, $\alpha=.91$. Surrogates reported average trait levels of anxiety on the STAI-T and internal consistency reliability was excellent, $\alpha=.88$. However, surrogates reported very high levels of anxiety specific to the COVID-19 pandemic (skew = 1.79) on a 9-point scale. Surrogates reported minimal depressive symptoms on the CESD-R. Internal consistency reliability for the CESD-R was excellent, $\alpha=.98$.

Surrogates reported very high levels of anxiety specific to COVID-19 (skew = -1.79). Patients also reported elevated levels of worry regarding the virus, skew $=-1.32$. A square root transformation was performed on skewed variables for use in subsequent analyses.

\section{Interpersonal variables}


Surrogates reported moderate levels of trust in the medical profession on the TIMPS. Internal consistency reliability for the TIMPS was good, $\alpha=.84$. On the CBESS, surrogates reported receiving generally sound emotional support from their partners. Internal consistency reliability was excellent $(\alpha=.90)$ for the current sample.

When reporting on behalf of their partners on the RBO, surrogates estimated the importance of avoiding being a burden on others as being moderate to strong. For the current sample, internal consistency reliability for the RBO was good, $\alpha=.79$. Surrogates reported moderately high feelings of similarity towards their partners on values related to end-of-life on the combined QLVI and LVI measure. Internal consistency reliability was excellent $(\alpha=.91)$ for the current sample. For use in the regression analysis predicting agreement scores, patients also completed the QLVI and the LVI. A difference score was calculated between patients' and surrogates' perceptions of their similarity on these values-related items. Discrepancies between surrogates' and patients' perceived similarities on values was as high as 49 points on the combined scale, with an average difference of $17.05(S D=11.73)$.

\section{Comparisons between recruitment sources}

Independent-samples t-tests evaluated differences between the participant groups recruited from MTurk and Mountaineer ENews on key study variables. Surrogates significantly differed across recruitment methods on the following variables: willingness to assume responsibility for medical decisions, trust in the medical profession, anxiety, COVID-19-related worry, religiosity, and the extent to which they reported discussing end-of-life preferences with their partners. Specifically, surrogates recruited from ENews reported higher levels of anxiety $(t$ $(152)=-3.65, p<.05)$, COVID-19-related worry $(t(152)=-2.34, p<.05)$, religiosity $(t(149)=-$ 
$1.52, p<.05)$, and greater willingness to take responsibility for medical decisions, $t(147)=-$ $3.09, p<.05$.

Among patients, a similar pattern emerged such that those recruited from ENews reported higher levels of COVID-19-related worry $(t(151)=-3.35, p<.005)$ and anxiety $(t(151)=-2.00$, $p<.05)$. Differences in anxiety and COVID-19-related worry may be attributed to the fact that MTurk participants were recruited at a slightly earlier point during the global pandemic, when pandemic-related stressors and restrictions were relatively new.

Finally, surrogates from ENews indicated lower levels of trust in the medical profession $(t(147)=.831, p<.05)$ and reported that they had engaged in relatively more discussion about end-of-life treatment with their partners, $t(152)=-1.132, p<.05$. Patients recruited through ENews were more likely to approve treatment interventions than those recruited through MTurk, $t(151)=-2.64, p<.05$. However, agreement scores did not significantly differ across recruitment groups. For both patients and surrogates, no significant demographic differences were detected across recruitment samples.

\section{Treatment selection and accuracy}

Across the decision vignettes, surrogates tended to approve administration of treatment, with an average treatment intervention score of 5.63 on the 7-point intervention selection scale. Notably, $42.9 \%$ of surrogates indicated that they would choose to provide treatment in all 7 vignettes. For patients, there was also a tendency to approve treatment options, with an average score of 5.46, and $39.2 \%$ of patients desiring provision of treatment in all 7 vignettes. The kappa statistic was calculated to measure agreement between patient-surrogate pairs. Kappa is a measure of agreement that is favored in the surrogate decision-making accuracy literature to date, since it provides a measure of agreement that is corrected for chance agreement, unlike 
percent agreement. Across the decision vignettes, agreement between patients and their surrogates on treatment selections was worse than that which would be expected by chance alone, kappa $=.268, p<.000$. Guidelines from Cicchetti and Sparrow (1981) classify this level of agreement as "poor." Of the 154 pairs, $46.1 \%$ agreed on all seven decision scenarios; therefore, $53.9 \%$ of the sample featured a surrogate inaccurately predicting the patient's preferences on at least one treatment decision. When predicting preferences, surrogates could err by "overtreating," or providing interventions that the patient would not have selected, or by "undertreating" and withholding a desired intervention. Of the 80 pairs in which the surrogate inaccurately predicted preferences for at least one scenario, $49(61.2 \%)$ featured the surrogate undertreating, while 31 (38.8\%) indicated overtreating.

When evaluating agreement for each decision vignette individually, agreement was lowest for the decision regarding ventilation, in which $75.6 \%$ of pairs agreed on the decision, and highest for the decision pertaining to coronary bypass surgery, $88.8 \%$ agreement; see Table 3 .

Surrogates reported a relatively high degree of treatment understanding across the 7 vignettes and reported that they had discussed end-of-life treatment preferences with patients to a moderate extent; see Table 5.

Research Question 1. To what extent are the selected intrapersonal and interpersonal variables related to accuracy? Do the variables predict surrogates' accuracy when attempting to execute the substituted judgment standard on hypothetical surrogate end-of-life treatment decisions?

First, bivariate correlation analyses revealed significant relations between accuracy and several of the variables individually (see Table 4). In terms of intrapersonal variables, surrogates' accuracy when predicting preferences was positively correlated with levels of empathy and 
religiosity, $r(154)=.25, p<.005 ; r(151)=.24, p<.005$, respectively. Therefore, surrogates who reported higher levels of these constructs were more accurate. Surrogates' levels of trust in the medical profession were also positively correlated with accuracy, $r(154)=.18, p<.05$.

When considering their partners' values, surrogates who reported greater perceived similarity to their patients regarding end-of-life values and who perceived their partners as more reluctant to burden others tended to be more accurate, $r(154)=.26, p<.005$ and $r(152)=.18, p$ $<.05$, respectively. Pairs who reported high discrepancies in perceived similarity on end-of-life values (e.g., the patient reported low similarity while their surrogate reported high similarity, and vice versa) were those in which surrogates were better predictors of treatment preferences, $r$ $(154)=.22, p<.05$.

According to a series of one-way ANOVAs, accuracy did not significantly differ across various demographic variables, including the surrogate's gender, marital status, ethnicity, religious preference, or relationship to the patient. According to an independent-samples t-test, surrogates who reported prior experience serving as a surrogate were more likely to accurately predict patient preferences than those who denied such experience, $t(151)=4.59, p<.05$.

Significant correlates were then included in a multiple linear regression analysis to evaluate the prediction of surrogates' accuracy. The criterion variable was accuracy, operationalized as total agreement scores computed across the seven vignettes, ranging from 0 to 7. Specifically, the following predictor variables were used: surrogates' ratings of trust, religiosity, empathy, perceived similarity to patients on end-of-life values, perceived degree of patients' reluctance to burden others, and differences between patients and surrogates on end-oflife values. Collinearity diagnostics, variance inflation factors, and tolerance values were within normal limits. Conditioning plots and Levene's test supported assumptions of equality of 
variances and normal distributions. The overall predictive model was significant, $F(6)=3.03, R^{2}$ $=.12, p=.008$. None of the variables appeared as unique predictors; see Table 7 .

Follow-up analyses. In an exploratory linear regression analysis, all of the intrapersonal and interpersonal variables of interest were used to predict surrogates' intervention selections. In other words, these variables were used to predict surrogates' tendencies to approve treatment administration in the decision vignettes. The variables significantly predicted treatment selection, $F(16)=2.28, R^{2}=.24, p=.006$. Of the predictor variables, the only unique predictor was COVID-19-related anxiety, $\beta=.28, p<.005$.

\section{Research Question 2. How does the prediction of accuracy differ based on the type}

of decision being made? Separate logistic regression analyses were conducted for each of the seven decision vignettes individually, using all of the intrapersonal and interpersonal variables of interest as predictors. Variables were used to predict agreement scores (scored as $0=$ agree, or 1 $=$ disagree) for each decision individually. Three of the seven decision scenarios produced significant predictive models.

For the decision regarding whether to administer ventilation, the logistic regression model was statistically significant, $X^{2}(16)=31.24, p<.05$. The model explained $30.1 \%$ (Nagelkerke $R^{2}$ ) of the variance in agreement and correctly classified $79.9 \%$ of cases. Greater empathy and perceived similarity to patients on end-of-life values was associated with an increased likelihood of agreement on this decision.

The logistic regression model was also statistically significant for the decision of whether to provide dialysis treatment, $X^{2}(16)=29.95, p<.05$. The model explained $35.2 \%$ (Nagelkerke $R^{2}$ ) of the variance in agreement and correctly classified $87.3 \%$ of cases. Of the predictive variables, surrogates who reported less desire to take personal responsibility for medical 
decisions tended to provide more accurate predictions of their partners' preferences with regards to dialysis treatment.

Finally, for the decision regarding whether to provide cardiac bypass surgery, the logistic regression model was statistically significant, $X^{2}(16)=29.00, p<.05$. The model explained $38.6 \%$ (Nagelkerke $R^{2}$ ) of the variance in agreement and correctly classified $90.3 \%$ of cases. According to surrogates' reports, engaging in greater discussion of end-of-life preferences with their partners was associated with greater agreement on this decision. Greater empathy and perceived similarity to patients on end-of-life values was associated with an increased likelihood of agreement on this decision. In other words, the combination of empathy and perceived similarity levels were predictive of surrogates' accuracy when predicting preferences.

The logistic regression models pertaining to the interventions of CPR, a feeding tube, chemotherapy, and amputation were not statistically significant.

\section{Research Question 3. What patient-reported variables predict accuracy?}

Since similar data were collected for both patient and surrogate participants, a multiple linear regression analysis also evaluated the prediction of total agreement scores across all seven vignettes using patient-reported intrapersonal and interpersonal variables as predictors. The criterion variable was total agreement scores, ranging from 0 to 7 , across the seven vignettes. Collinearity diagnostics, variance inflation factors, and tolerance values were within normal limits. Conditioning plots and Levene's test supported assumptions of equality of variances and normal distributions. The overall predictive model was not significant, $F(16)=1.84, R^{2}=.16, p$ $=.06$.

\section{Discussion}


The current study aimed to replicate and extend Hare and colleagues' (1992)

investigation of surrogate medical decision-making accuracy by examining decision making between patient-surrogate pairs on hypothetical treatment decision vignettes. In addition to examining the relation between accuracy and specific variables, the study evaluated the extent to which surrogates accurately predicted patients' preferences. Variables were drawn from two categories: intrapersonal variables pertaining to surrogates themselves, and interpersonal variables related to surrogates' relationships with their patient partners, perceptions of their partners, and views of the medical profession in general.

The following were considered as intrapersonal variables in the primary analyses: surrogates' age, education level, self-rated physical health, COVID-19-related anxiety, religiosity, trait-level anxiety, depression, empathy, understanding of costs and benefits related to treatment options, willingness to assume full responsibility for decisions. Interpersonal variables included: surrogates' trust in the medical profession, surrogates' perceived emotional support from partner, surrogates' perception of the extent to which the patient is reluctant to burden others, extent to which surrogate has communicated with partner about end-of-life treatment preferences, surrogates' perceived similarity to patients on end-of-life values, and differences between surrogates' and patients' perceived similarity on end-of-life values. Furthermore, this study investigated whether accuracy and related variables differed across the vignettes, since each vignette dealt with a different treatment intervention.

\section{Surrogates' accuracy on decision vignettes}

In concordance with Hare and colleagues' (1992) findings, and a preponderance of evidence from the surrogate decision-making accuracy literature (Shalowitz, 2002; Spalding, 2020), surrogates predicted patients' preferences with poor accuracy across the decision 
vignettes. Specifically, surrogates predicted preferences with accuracy that was significantly worse than that which would be expected by chance alone. This finding adds to the body of evidence suggesting that individuals who make decisions for patients in end-of-life situations may not be trusted to consistently select the treatment that the patient would have wanted (Torke, 2008). The level of agreement found in the current study is notably lower than that reported in a systematic review of the literature by Shalowitz et al. (2006; $68 \%$ agreement, on average), yet it is consistent with levels reported by more recent investigations of surrogate decision-making accuracy (e.g., Bravo et al., 2017).

Among pairs in which surrogates inaccurately predicted preferences on one or more decisions, there was a tendency for surrogates to undertreat and fail to provide treatment that the patient would have desired. Prior surrogate decision-making accuracy research has revealed inconclusive patterns of surrogate inaccuracy; some studies have reported no differences in overtreatment versus undertreatment errors (e.g., Moorman \& Carr, 2008), while others have documented a slight tendency for surrogates to overtreat (e.g., Fagerlin et al., 2001) and undertreat (e.g., Bravo et al., 2017). The current findings are more consistent with literature regarding discrepancies in estimating levels of pain or discomfort experienced by others. In particular, the surrogate decision-making literature reflects that surrogates are only moderately successful when gauging levels of pain experienced by the patients they serve (Desbiens \& Mueller-Rizner, 2000) and that surrogates tend to underestimate patients' perceptions of an acceptable quality of life (Bravo et al., 2017).

There are undoubtedly mediating and moderating factors that may influence surrogates' propensities to undertreat. For instance, "empathy gaps" may inhibit the surrogate's ability to accurately adopt the perspective of the patient in a situation of critical illness or disability 
(Loewenstein, 2005). The concept of the "disability paradox" is relevant to the medical decisionmaking literature (Ubel et al., 2005) and speaks to the mechanism by which undertreatment errors may occur, since individuals may fail to appreciate the ease with which others can adapt to poor health conditions and situations of impairment or discomfort. Certainly, the issue of undertreatment raises ethical issues that have prompted medical ethicists (e.g., Gillick \& Fried, 1995) to advocate for revising standards of surrogate decision making beyond the substituted judgment standard, perhaps more strictly enforcing a standard of "best interest" standard that restricts surrogates from violating explicit treatment norms of the medical profession.

The discrepancy in treatment decisions between patients and surrogates is particularly alarming given that surrogates reported that they felt they understood the costs and benefits related to the vignettes relatively well, and that they had discussed end-of-life preferences with patients to some extent. Prior research has documented a propensity for surrogates to reflect that they feel more equipped to make decisions when they have discussed patients' preferences in advance (e.g., Batteux, Ferguson, \& Tunney, 2020; Schenker et al., 2012). Engaging in prior discussions may be associated with improved accuracy in some cases, but not all. Surrogates' reports of prior discussions with patients predicted accuracy only for the decision vignette pertaining to cardiac bypass surgery. Of the decision vignettes used in this study, the cardiac bypass vignette also demonstrated the highest level of percent agreement between patients and surrogates. Coronary artery bypass is among the most common surgical interventions performed in the United States (Johns Hopkins Medicine, 2020) and participants may have had greater familiarity with this procedure relative to the other interventions presented in the study. Research indicates that patients who report greater familiarity with interventions, particularly those related to cardiovascular surgery, seek more participation when making decisions pertaining to these 
interventions (Mansell et al., 2000). If cardiac bypass was an intervention for which patients and surrogates had greater familiarity or held more similar preferences, surrogates may have been more inclined to be accurate on this vignette. Prior discussions of preferences may have particularly bolstered this effect.

However, the evidence regarding whether discussion-based interventions targeting endof-life preferences improves surrogate decision-making accuracy is mixed (Lord, Livingston, \& Cooper, 2015; Shalowitz, 2006). The current study further reflects how surrogates' confidence in the value of engaging in prior discussions about end-of-life care is not strongly tied to their accuracy. An explanation for this occurrence may be that surrogates overvalue the degree to which these conversations truly facilitate their abilities to execute the substituted judgment standard and select the intervention that the patient would choose. For instance, surrogates may report that they discuss end-of-life preferences quite frequently with patients, but these conversations may lack the depth and specificity required to accurately identify a preferred course of treatment. Hence, surrogates may misinterpret higher-frequency discussions as being of higher-quality, producing an inflated assessment of one's knowledge of treatment options and patient preferences. Values related to end-of-life decisions are complex, and surrogates may unwittingly adopt a myopic, oversimplified view of treatment decisions (Scheunemann \& White, 2011). For instance, surrogates may fail to appreciate the number and variety of values implicated in a treatment decision and focus too narrowly on a single identified value, such as the desire to sustain life at any cost (Swindell, McGuire, \& Halpern, 2010).

In light of evidence that surrogates' approaches to decision making vary based on the type of treatment decision being made (Spalding \& Edelstein, 2020), accuracy was also examined for each decision vignette individually. Patient-surrogate agreement was lowest for the 
decision concerning whether to provide ventilation, while it was highest for the decision regarding coronary bypass surgery (see Table 3). Participants' approaches to the decision vignette regarding ventilation in particular must be considered in the unique context of the global pandemic during which data collection occurred. COVID-19, a disease with symptoms primarily affecting the respiratory system, can produce severe complications such as pneumonia that require the use of mechanical ventilation (Dondorp et al., 2020). During the pandemic, estimates of the number of needed ventilators in the United States ranged from several hundred thousand to over one million (Fink, 2020). The country's insufficient ability to meet this demand was well-broadcast and concerns for the adequate provision of critical care supplies were raised (Ranney et al., 2020). Such heightened public attention towards mechanical ventilation may have prompted participants to reexamine their views towards this treatment option in particular, such that patients' personal desires to receive ventilation may have shifted, unbeknownst to their surrogates. Therefore, surrogates may have been less accurate on this decision because they chose decisions based on understandings of what patients may have selected before the pandemic, knowledge of how patients' views towards this treatment option may have changed due to recent circumstances.

\section{Variables related to overall accuracy on decision vignettes}

Several interesting relations emerged to enhance understandings of potential mechanisms underpinning surrogates' accuracy. Specifically, the following were associated with accuracy: surrogates' trust, empathy, religiosity, perceived similarity on end of life values, and perceptions of patients' reluctance to burden others. Differences between surrogates and patients on end-oflife values was also associated with accuracy. When taken altogether, these variables 
significantly predicted surrogates' accuracy when completing hypothetical decision tasks, although none of the variables were unique predictors.

The relation between agreement and empathy is consistent with understandings of empathy as a construct that promotes perspective-taking (Lamm et al., 2007). Moreover, the observed role of empathy may have been particularly pronounced given the age of the recruited sample ( $M_{\text {age }}=47$ years for patients, 51 years for surrogates), as empathy tends to peak in middle-adulthood (O'Brien et al., 2013), the life stage that characterized the majority of the current sample.

The importance of interpersonal empathy, as identified by the current study, contributes to understandings of "cold to hot" interpersonal empathy gaps that may occur when individuals make medical decisions on behalf of others. "Cold to hot" empathy gaps refer to a situation in which a person is in an emotionally "cold" or neutral state and attempts to make a decision or prediction about behaviors, preferences, or feelings that may occur in a future emotionally "hot" state (Loewenstein, 2005). In medical decision making, this type of empathy gap can result in the treatment decision-maker underappreciating the amount of pain and discomfort experienced by a patient. This phenomenon has most often been investigated to the extent that it applies to physicians' tendencies to undertreat patients' pain (Loewenstein, 2005), but surrogates could also fall prey to interpersonal empathy gaps and select less intensive treatment interventions than the patient would have desired. As suggested by the current study, surrogates with lower levels of empathy might consequently be less accurate when predicting patient preferences. Indeed, among surrogates who inaccurately predicted preferences on one or more decision scenarios, there was a tendency to err by undertreating. Therefore, empathy may have been a source of this discrepancy, which warrants examination in future work. 
Accuracy was also positively correlated with religiosity, such that surrogates with greater self-reported religiosity were more accurate when predicting preferences. This is the first study to specifically examine religiosity relative to surrogate decision-making accuracy. Although religiosity was not significantly correlated with empathy, which may have illustrated a mechanism by which surrogates higher in religiosity were better able to predict preferences, an alternative explanation for this relation could lie in previously demonstrated positive associations between religiosity and personality variables not assessed by the current study, such as conscientiousness (Henningsgaard \& Arnau, 2008). Surrogates who report greater religiosity may be those who are more conscientious, and who therefore completed the decision activity with greater care and attention to patient preferences. Some evidence suggests inverse associations between surrogates' religiosity and patients' receipt of life-sustaining treatments (Torke et al., 2020), such that surrogates who endorse greater religiosity are less likely to select life-sustaining treatments for patients. This correlation pattern was not evident when religiosity was examined relative to surrogates' intervention selections on decision vignettes.

Rather, the current findings are more consistent with evidence from the religious coping literature that illustrates associations between religious coping behaviors, such as seeking support through faith communities during times of stress, and end-of-life treatment. For instance, Phelps and colleagues (2009) found that advanced cancer patients who reported strong engagement in religious activities to cope with their illness were more likely to receive intensive life-prolonging treatments at end-of-life. Of note, this study examined patients' reports of their own participation in religious coping. Relations between surrogates' religious coping behaviors while serving as a surrogate and the decisions they make on the patient's behalf have not yet been determined. 
Surrogates who were more accurate predictors of patient preferences also tended to be those who reported greater trust in the medical profession. Theoretical conceptualizations of surrogate decision making have proposed that low trust in the medical profession may hinder surrogates' decision making and reduce the overall quality of their decisions (e.g., Meeker, 2004; Torke et al., 2014). As the first investigation to specifically examine trust in the medical profession as it relates to surrogate decision-making accuracy, the current study provides preliminary support for these conjectures.

Perceiving the patients' values as more similar to one's own (as measured by ratings on the Quality of Life and Life Values Index) was also associated with surrogates' accuracy. This is consistent with prior research evaluating surrogates' execution of the substituted judgment standard and their reflections of the process, such that surrogates often state that they rely on known mutual interests between themselves and the patient to guide their decisions (Vig et al., 2006). However, other researchers caution that high perceived similarity can undermine decision making if surrogates mistakenly interpret their own values as identical to those of the patient (Fagerlin et al., 2002). Contrary to findings by Winter and Parks (2012), differences in surrogates' estimates of patients' reluctance to burden others and patients' own self-reported levels of reluctance were not associated with accuracy.

\section{Variables related to accuracy on individual decision vignettes}

Although the regression model predicting accuracy as computed across all decision vignettes was not significant, the variables did predict accuracy for certain vignettes when they were examined individually. Specifically, the predictive model was significant for decisions regarding the provision of ventilation, dialysis treatment, and cardiac bypass surgery. This finding aligns with previous work (Spalding \& Edelstein, 2020) reflecting how treatment options 
may differentially evoke certain decision-making approaches by surrogates, in terms of their desire to collaborate with patients' physicians and assume full responsibility for decisions. These differences may be due to the fact that presented treatments differ in the amount of risk they involve, and the extent to which such risk is considered worthwhile in the context of the decision (Sitkin \& Weingart, 1995). For instance, when making decisions about treatments that confer more immediate and substantial risks (e.g., CPR, which presents associated risks of broken ribs and punctured lungs, but which will likely result in immediate death if not provided), the degree of confidence a surrogate has in their decision-making ability is associated with the extent to which they desire collaboration with providers (Spalding \& Edelstein, 2020).

With regard to the decision pertaining to mechanical ventilation, surrogates' empathy and perceived similarity to patients on key values emerged as unique predictors of agreement on decisions. This is consistent with prior findings such as those from McDade-Montez, Watson, and Beer (2013), reflecting that spouses who perceive greater similarities to their partners on values pertaining to end-of-life tend to be more accurate when predicting partners' treatment preferences. For the dialysis treatment decision vignette, surrogates who reported less willingness to take full responsibility for medical decisions were more likely to accurately predict patient preferences. This finding is concerning if surrogates who are more likely to defer decision making to providers are those who actually better understand patients' preferences, and who would make a decision in closer alignment with patient preferences. However, the current study cannot provide behavioral evidence as to whether surrogates' decision-making behaviors match their preferences for decisional responsibility. In other words, despite feeling uncomfortable with the decisional role, surrogates may nonetheless make decisions for patients without deferring to a provider in real treatment decision situations. This would be consistent 
with reports that observed communication behaviors between patients and providers do not differ significantly based on patients' reported communication preferences (Kumar et al., 2010).

Lastly, as previously discussed, surrogates' reports of prior engagement in discussions of end-of-life preferences with their partners predicted greater accuracy on the cardiac bypass decision vignette. This relation corroborates prior findings that such discussions tend to improve surrogates' decision making, as measured both by surrogates' self-reported ease with decision making and the accuracy of the decisions they made when compared to those of their partners (e.g., Batteux, Ferguson, \& Tunney, 2020). Similar to relations observed for the mechanical ventilation vignette, greater empathy and perceived similarity to patients on end-of-life values was associated with an increased likelihood of agreement on the cardiac bypass decision.

\section{Variables related to intervention selection}

Given that the main regression analysis predicting agreement scores was not significant, an exploratory analysis investigated the predictive role of the interpersonal and intrapersonal variables with respect to surrogates' treatment choices on the decision vignettes. In other words, these variables were used to predict surrogates' tendencies to approve treatment administration. It is noteworthy that the interpersonal and intrapersonal variables significantly predicted treatment selection, $F(16)=2.28, R^{2}=.24, p=.006$. Of the predictor variables, the only unique predictor was COVID-19-related anxiety $(\beta=.28, p<.005)$ such that surrogates with greater anxiety about COVID selected more intensive treatments for patients.

Although current understandings of COVID-19-related anxiety are nascent, this specific type of anxiety demonstrates positive relations with anxiety and depressive disorder symptoms (Asmundson et al., 2020), which was also evident in the current study (see Table 4). Moreover, anxiety about COVID appears to be associated with feelings of hopelessness and the use of 
maladaptive coping mechanisms (e.g., drugs and alcohol; Lee, 2020). Importantly, these negative emotions and coping behaviors pertain to oneself and one's current situation, not involving another person. In the current study, surrogates were acting on behalf of another person to whom they were presumably close. Evidence from the self-other decision-making literature reflects that individuals often choose different decisions for another person than they would for themselves; for instance, they are more likely to make a "safer" choice than they would for themselves in situations where risk aversion is valued (Stone et al., 2013). Therefore, surrogates may have chosen an intensive treatment intervention to "save" the patient in these vignettes, despite feeling pessimistic about their personal circumstances in the emotionally distressing context of a global pandemic. Ultimately, more research is needed regarding the relation between perceptions of COVID and treatment preferences, specifically with regard to self-other decision-making discrepancies.

\section{Limitations and Future Directions}

As with any study, limitations exist. First, hypothetical scenarios can only model a realworld decision-making scenario, and these findings are therefore limited with respect to generalizability. For instance, surrogates may be vulnerable to a "cold-to-hot" empathy gap (Loewenstein, 2005) when completing hypothetical medical decision vignettes, such that they underestimate the force of motivational and affective pressures that occur in the emotionally "hot" conditions of a real treatment decision situation. However, logistical constraints of gathering data at the exact moment at which surrogate decision making takes place, particularly during a pandemic that limited access to healthcare facilities, impeded this possibility. Related to the design of this study, a common concern raised with regard to hypothetical surrogate decisionmaking tasks is the fact that surrogates may struggle with the perspective-taking effort required. 
For instance, surrogates may misread or misunderstand the instructions of the decision task and make decisions more in accordance with their own preferences. However, this issue is a concern in real-life surrogate decision-making situations (Marks \& Arkes, 2008), and the design of the current study permitted the evaluation of this tendency by assessing agreement between patients and surrogates on the vignettes.

Of further relevance to generalizability, limitations exist with respect to certain features of the recruited patient-surrogate dyads. The majority of pairs in the current study were those in which a female was serving as a surrogate on behalf of a male patient, most often in the context of a spousal or romantic partnership. As previously described, gender differences in medical surrogate decision-making accuracy among marital partners have been documented, such that wives tend to be more accurate than their husbands in hypothetical surrogate decision making scenarios (Zettel-Watson et al., 2005). Therefore, the level of agreement on surrogate decisionmaking tasks reported by the current study may overestimate that which occurs in surrogate decision-making situations featuring a male surrogate serving on behalf of female patients.

With respect to demographic characteristics, participants were relatively well-educated, in generally good health, and identified as White/Caucasian. As such, the recruited sample underrepresents the diverse population of patients, and their associated surrogates, who are encountered in United States intensive care units where end-of-life surrogate decision-making often occurs (Barker, 2006). Patient-surrogate pairs of minority backgrounds are important to investigate, as medical decision-making tendencies can vary considerably across groups. For instance, among Black and Latinx individuals, those who reported a lower level of educational attainment preferred more intensive medical treatment options (Volandes, Ariza, et al., 2008; Volandes, Pasche-Orlow, et al., 2008). Alarmingly, patients of racial and ethnic minority 
backgrounds tend to receive end-of-life care that is inconsistent with their stated preferences (Mack et al., 2010) and families of these individuals demonstrate greater conflict and discord during the end-of-life decision-making process (Muni et al., 2011). Among patients in intensive care units, those with limited English proficiency also have lower rates of advance directive completion, necessitating the consultation of a surrogate if one is available (Barwise et al., 2018), and tend to receive more aggressive end-of-life treatment (Yarnell et al., 2017).

To improve generalizability, future investigations may prioritize investigating surrogate decision-making accuracy with different combinations of patient-surrogate relationships. These might include pairs of siblings, grandparents and grandchildren, close friends, and more distant relatives. Most of the pairs recruited for the current study were spouses or romantic partners. Spousal and romantic relationships are presumably quite close in terms of emotional intimacy and familiarity. Research investigating actor-partner models of decision making indicates that pairs who report greater feelings of familiarity form more positive appraisals of the decisionmaking process when collaborating on decisions with each other (Margrett \& Marsiske, 2002). This may translate into the realm of surrogate decision making such that pairs who feel closer to one another are more comfortable with making decisions on each other's behalf and be more likely to agree with each other on decisions. In one investigation of a communication intervention designed to improve patient-surrogate agreement on end-of-life decisions (SUPPORT, Marbella et al., 1998), the intervention actually reduced agreement among pairs who were not immediate family members, indicating that communication about decisions operates differently for these types of pairs. Future work might examine this issue more closely, perhaps with the aim of generating decision support tools for patient-surrogate pairs who are more distantly related. 
Future investigations could investigate relations reported by the current study with attention to the potential involvement of mediating or moderating variables. Although not assessed by the current study, the role of surrogates' personality characteristics bears consideration in light of evidence from the patient medical decision-making literature. For instance, patients with high levels of conscientiousness and openness tend to prefer more active involvement in decision making (Djanetliev \& German, 2013), while those who score low in extraversion report feeling dependent on a provider's expertise and are more likely to defer decision-making authority (Shay \& Lafata, 2014). Neurotic patients also report greater anxiety associated with medical decision making (Weston, Hill, \& Jackson, 2015) and tend to choose less risky treatment options (Lauriola \& Levin, 2001). The extent to which these relations are similar for surrogates, and may influence their accuracy when predicting patient preferences, has yet to be examined.

Gender differences in surrogate decision-making accuracy also warrant exploration, perhaps to investigate whether surrogates are more accurate when predicting preferences for a patient who identifies as the same gender. Further, given that male patients are more likely to prefer intensive treatment options than females (Bookwala et al., 2001), the extent to which similar differences exist for surrogates when choosing treatments for patients could be examined. Additionally, in light of findings from this study indicating that surrogates may differ in the extent to which they "overtreat" or "undertreat" when selecting treatments for patients, future research could further explore variables related to overtreating or undertreating tendencies. Ultimately, such findings could be used to specifically classify "types" of surrogate decision makers, in order to allow providers to better anticipate the interventions surrogates may choose and assist them with the decisional process accordingly. 
With regard to measurement techniques, work conducted during the COVID-19 pandemic may prioritize the psychometrically sound assessment of COVID-19-related anxiety, a variable with demonstrated importance in the current study. At the time of study design, no validated assessment measures of this construct existed, and a single-item measure was subsequently used. Since completion of data collection, researchers have begun to design and validate assessment measures to more comprehensively capture COVID-19-related anxiety. In particular, the five-item Coronavirus Anxiety Screener (Lee, 2020) demonstrates good reliability and validity evidence and would be a valuable resource for use in future studies. The extent to which COVID-19-related anxiety differs from health anxiety more generally also merits further exploration.

Finally, research employing hypothetical surrogate decision-making vignettes might examine the extent to which surrogates have engaged in discussions with patients for specific decisions. In the current study, surrogates' accuracy and self-reported levels of treatment understanding were not consistent across the decision vignettes. Pairs may discuss more commonly administered interventions (e.g., CPR, coronary bypass surgery) with greater frequency and detail than others. These findings speak to the importance of considering decisionspecific support for surrogates when making decisions on behalf of patients. For instance, ample patient decision guides and tools exist to aid with medical decisions, such as those relating to mechanical ventilation or dialysis (e.g., Mayo Clinic Shared Decision Making Resource Center; see Cardona-Morrell et al., 2017 for a review), and could be similarly adapted for use with surrogates. When creating decision support tools, providers may also con

\section{Conclusions}


The current study further amplifies concerns for surrogates' accuracy, and their ability to execute the substituted judgment standard, by revealing inconsistencies in patient-surrogate agreement when selecting treatment interventions. Certain interpersonal and intrapersonal variables, as reported by surrogates, predicted accuracy across all decision vignettes. These variables include surrogates' religiosity, trust in the medical profession, empathy, perceived similarity to patients on values related to end-of-life, and perceptions of patients as being more reluctant to burden others. Examination of accuracy for individual decision vignettes provided further evidence that surrogate medical decision making varies based on the type of treatment decision that is being made.

The selected variables in this study significantly predicted surrogates' intervention selections on behalf of patients. Of the predictor variables, surrogates with greater anxiety about COVID selected more intensive treatments for patients. Findings from this broad, exploratory study can be used to further the development of targeted decision-making interventions to improve surrogates' accuracy. Providers may attend to these variables when working with surrogates in their decision-making role. For instance, during the current pandemic, providers may specifically attend to facilitating surrogates' trust in the medical profession and ability to cope with anxiety surrounding COVID-19. 


\section{References}

Ahmed, F., Ahmed, N. E., Pissarides, C., \& Stiglitz, J. (2020). Why inequality could spread COVID-19. The Lancet Public Health, 5(5), e240.

Anderson, W. G., Arnold, R. M., Angus, D. C., \& Bryce, C. L. (2009). Passive decision-making preference is associated with anxiety and depression in relatives of patients in the intensive care unit. Journal of Critical Care, 24(2), 249-254. doi:10.1016/j.jcrc.2007.12.010

Angie, A. D., Connelly, S., Waples, E. P., \& Kligyte, V. (2011). The influence of discrete emotions on judgement and decision-making: A meta-analytic review. Cognition \& Emotion, 25(8), 13931422. doi:10.1080/02699931.2010.550751

Armstrong, K., Rose, A., Peters, N., Long, J. A., McMurphy, S., \& Shea, J. A. (2006). Distrust of the health care system and self-reported health in the United States. Journal of general internal medicine, 21(4), 292. doi:10.1111/j.1525-1497.2006.00396.x

Arora, N. K., \& McHorney, C. A. (2000). Patient preferences for medical decision making: who really wants to participate?. Medical Care, 33five-341. doi:10.1097/00005650-200003000-00010

Asmundson, G. J., \& Taylor, S. (2020). How health anxiety influences responses to viral outbreaks like COVID-19: What all decision-makers, health authorities, and health care professionals need to know. Journal of Anxiety Disorders, 71, 102211.

Avtgis, T. A. (2003). Male sibling social and emotional support as a function of attributional confidence. Communication Research Reports, 20(4), 341-347. doi:10.1080/08824090309388833

Azoulay, E., Pochard, F., Kentish-Barnes, N., Chevret, S., Aboab, J., Adrie, C., \& Fassier, T. (2005). Risk of post-traumatic stress symptoms in family members of intensive care unit 
patients. American journal of respiratory and critical care medicine, 171(9), 987-994. doi:10.1164/rccm.200409-1295oc

Baker, M.E. (2002). Economic, political and ethnic influences on end-of-life decision making: A decade in review. Journal of Health and Social Policy, 14, 27-39. doi:10.1300/j045v14n03_02

Balkrishnan, R., Dugan, E., Camacho, F. T., \& Hall, M. A. (2003). Trust and satisfaction with physicians, insurers, and the medical profession. Medical Care, 41(9), 1058-1064. doi:10.1097/01.mlr.0000083743.15238.9f

Barker, J. A. (2006). Use of Intensive Care at the End of Life in the United States: An Epidemiologic Study. Yearbook of Pulmonary Disease, 293-294. doi:10.1016/s0084-3873(08)70503-0

Barwise, A., Jaramillo, C., Novotny, P., Wieland, M. L., Thongprayoon, C., Gajic, O., \& Wilson, M. E. (2018). Differences in Code Status and End-of-Life Decision Making in Patients With Limited English Proficiency in the Intensive Care Unit. Mayo Clinic Proceedings, 93(9), 1271-1281. doi:10.1016/j.mayocp.2018.04.021

Batteux, E., Ferguson, E., \& Tunney, R. J. (2020). A mixed methods investigation of end-of-life surrogate decisions among older adults. BMC Palliative Care, 19(1). doi:10.1186/s12904-02000553-w

Bausewein, C., Calanzani, N., Daveson, B. A., Simon, S. T., Ferreira, P. L., Higginson, I. J., ... \& Ceulemans, L. (2013). 'Burden to others' as a public concern in advanced cancer: a comparative survey in seven European countries. BMC cancer, 13(1), 105. doi:10.1186/1471-2407-13-105

Bechara, A. (2004). The role of emotion in decision-making: evidence from neurological patients with orbitofrontal damage. Brain and cognition, 55(1), 30-40. doi:10.1016/j.bandc.2003.04.001

Beresford, E. B. (1991). Uncertainty and the Shaping of Medical Decisions. The Hastings Center Report, 21(4), 6. doi:10.2307/3562993Berger, J. T. (2010). What about process? Limitations in 
advance directives, care planning, and noncapacitated decision making. The American journal of bioethics, 10(4), 33-34. doi:10.1080/15265161003632948

Billings, J. A., \& Krakauer, E. L. (2011). On patient autonomy and physician responsibility in end-oflife care. Archives of internal medicine, 171(9), 849-853. doi:10.1001/archinternmed.2011.180

Bishop, F. L., \& Yardley, L. (2004). Constructing agency in treatment decisions: negotiating responsibility in cancer. Health, 8(4), 46five-482. doi:10.1177/1363459304045699

Blanchard, C. G., Labrecque, M. S., Ruckdeschel, J. C., \& Blanchard, E. B. (1988). Information and decision-making preferences of hospitalized adult cancer patients. Social science \& medicine, 27(11), 1139-1145. doi:10.1016/0277-9536(88)90343-7

Blendon, R. J., Szalay, U. S., \& Knox, R. A. (1992). Should physicians aid their patients in dying?: The public perspective. JAMA, 267(19), 2658-2662. doi:10.1001/jama.1992.03480190102042

Bookwala, Kristen M. Coppola, Angela Fagerlin, Peter H. Ditto, Joseph H. Danks, William D. Smucker, J. (2001). Gender differences in older adults' preferences for life-sustaining medical treatments and end-of-life values. Death Studies, 25(2), 127-149.

Bravo, G., Sene, M., \& Arcand, M. (2017). Surrogate inaccuracy in predicting older adults' desire for life-sustaining interventions in the event of decisional incapacity: is it due in part to erroneous quality-of-life assessments?. International Psychogeriatrics, 29(7), 1061.

Brown, R. F., Butow, P. N., Henman, M., Dunn, S. M., Boyle, F., \& Tattersall, M. H. (2002). Responding to the active and passive patient: flexibility is the key. Health Expectations, 5(3), 236-245. doi:10.1046/j.1369-6513.2002.00183.x

Cahill, E., Lewis, L. M., Barg, F. K., \& Bogner, H. R. (2009). "You Don't Want to Burden Them:" Older Adults' Views on Family Involvement in Care. Journal of Family Nursing, 15(3), 295-317. 
Cardona-Morrell, M., Benfatti-Olivato, G., Jansen, J., Turner, R. M., Fajardo-Pulido, D., \& Hillman, K. (2017). A systematic review of effectiveness of decision aids to assist older patients at the end of life. Patient Education and Counseling, 100(3), 425-435.

Charles, C., Gafni, A., \& Whelan, T. (1997). Shared decision-making in the medical encounter: what does it mean?(or it takes at least two to tango). Social science \& medicine, 44(5), 681-692. doi:10.1016/s0277-9536(96)00221-3

Chewning, B., Bylund, C. L., Shah, B., Arora, N. K., Gueguen, J. A., \& Makoul, G. (2012). Patient preferences for shared decisions: a systematic review. Patient education and counseling, 86(1), 9-18. doi:10.1016/j.pec.2011.02.004

Cicchetti, D. V., \& Feinstein, A. R. (1990). High agreement but low kappa: II. Resolving the paradoxes. Journal of clinical epidemiology, 43(6), 551-558. doi:10.1016/0895-4356(90)90159m

Cicchetti, D. V., \& Sparrow, S. A. (1981). Developing criteria for establishing interrater reliability of specific items: applications to assessment of adaptive behavior. American journal of mental deficiency.

Cicirelli, V. G. (1997). Relationship of psychosocial and background variables to older adults' end-oflife decisions. Psychology and Aging, 12(1), 72.

Cisler, J. M., \& Koster, E. H. (2010). Mechanisms of attentional biases towards threat in anxiety disorders: An integrative review. Clinical psychology review, 30(2), 203-216. doi:10.1016/j.cpr.2009.11.003

Cohen, S. \& Wills, T.A. (1985). Stress, social support, and the buffering hypothesis. Psychological Bulletin, 98(2), 310-357. 
Cohen-Mansfield, J., Droge, J. A., \& Billig, N. (1992). Factors influencing hospital patients' preferences in the utilization of life-sustaining treatments. The Gerontologist, 32(1), 89-95.

Cronbach, L. J. (1955). Processes affecting scores on "understanding of others" and "assumed similarity”. Psychological Bulletin, 52, 177-193. doi:10.1037/h0044919

Cope, L. C., Tully, M. P., \& Hall, J. (2019). An exploration of the perceptions of non-medical prescribers, regarding their self-efficacy when prescribing, and their willingness to take responsibility for prescribing decisions. Research in Social and Administrative Pharmacy, 16(2), 249-256. doi:10.1016/j.sapharm.2019.05.013

Curley, S. P., Eraker, S. A., \& Yates, J. F. (1984). An investigation of patient's reactions to therapeutic uncertainty. Medical Decision Making, 4(4), 501-511.

Davis, M.A. (1980). A multidimensional approach to individual differences in empathy. JSAS Catalog of Selected Documents in Psychology, 10.85.

Desbiens, N. A., \& Mueller-Rizner, N. (2000). How well do surrogates assess the pain of seriously ill patients?. Critical Care Medicine, 28(5), 1347-1352.

Dewey, M. E. (1983). Coefficients of agreement. The British Journal of Psychiatry, 143(5), 487-489. doi:10.1192/bjp.143.5.487

Djanatliev, A., \& German, R. (2013). Prospective healthcare decision-making by combined system dynamics, discrete-event and agent-based simulation. In Proceedings of the 2013 Winter Simulations Conference (WSC). (pp. 270-281). IEEE Press. doi:10.1109/wsc.2013.6721426

Dondorp, A. M., Hayat, M., Aryal, D., Beane, A., \& Schultz, M. J. (2020). Respiratory support in COVID-19 patients, with a focus on resource-limited settings. The American Journal of Tropical Medicine and Hygiene, 102(6), 1191-1197.

Doukas, D. J., \& McCullough, L. B. (1991). The values history. Journal of Family Practice, 32, 145-50. 
Eaton, W.W., Smith, C., Ybarra, M., Muntaner, C., Tien, A. (2004). Center for Epidemiologic Studies Depression Scale: review and revision (CESD and CESD-R), In: Maruish, M.E. (Ed.), The Use of Psychological Testing for Treatment Planning and Outcomes Assessment ( $3^{\text {rd }}$ ed). Instruments for Adults, 3. Lawrence Erlbaum, Mahwah, NJ, pp. 363-377.

Ellis, E.M., \& Ferrer, R.A. (2018). Affect and decision making in cancer. In D.M. Williams, R.E. Rhodes, \& M.T. Conner (Eds.), Affective determinants of health related behavior. Oxford University Press.

Elwyn, G., Frosch, D., Thomson, R., Joseph-Williams, N., Lloyd, A., Kinnersley, P., \& Edwards, A. (2012). Shared decision making: a model for clinical practice. Journal of general internal medicine, 27(10), 1361-1367. doi:10.1007/s11606-012-2077-6

Engel, K. G., Heisler, M., Smith, D. M., Robinson, C. H., Forman, J. H., \& Ubel, P. A. (2009). Patient comprehension of emergency department care and instructions: are patients aware of when they do not understand?. Annals of emergency medicine, 53(4), 454-461. doi:10.1016/j.annemergmed.2008.05.016

Fagerlin, A., Ditto, P. H., Hawkins, N. A., Schneider, C. E., \& Smucker, W. D. (2002). The use of advance directives in end-of-life decision making: Problems and possibilities. American Behavioral Scientist, 46(2), 268-283. doi:10.1177/000276402236678

Farrell, T. W., Widera, E., Rosenberg, L., Rubin, C. D., Naik, A. D., Braun, U. Ethics, Clinical Practice and Models of Care, and Public Policy Committees of the American Geriatrics Society. (2017). AGS position statement: making medical treatment decisions for unbefriended older adults. Journal of the American Geriatrics Society, 65(1), 14-15. doi:10.1111/jgs.14586 
Faro, D., \& Rottenstreich, Y. (2006). Affect, empathy, and regressive mispredictions of others' preferences under risk. Management Science, 52(4), 529-541.

Ferrer, R. A., Green, P. A., \& Barrett, L. F. (2015). Affective science perspectives on cancer control. Perspectives on Psychological Science, 10(3), 328-345. doi:10.1177/174569161557675

Fink, S. (2020). Worst-case estimates for US coronavirus deaths. New York Times.

Forgas, J.P. (1995). Emotion in social judgments: Review and a new affect infusion model (AIM). Psychological Bulletin, 117, 39-66.

Ganzini, L., Lee, M. A., Heintz, R. T., Bloom, J. D., \& Fenn, D. S. (1994). The effect of depression treatment on elderly patients' preferences for life-sustaining medical therapy. The American journal of psychiatry, 151(11), 1631.

Gay, E. B., Pronovost, P. J., Bassett, R. D., \& Nelson, J. E. (2009). The intensive care unit family meeting: making it happen. Journal of critical care, 24(4), 629-e1. doi:10.1016/j.jcrc.2008.10.003

Gillick, M. R., \& Fried, T. (1995). The limits of proxy decision making: undertreatment. Cambridge Q. Healthcare Ethics, 4, 172.

Green, S. B. (1991). How Many Subjects Does It Take To Do A Regression Analysis. Multivariate Behavioral Research, 26(3), 499-510. doi:10.1207/s15327906mbr2603_7

Grisso, T. \& Appelbaum, P. S. (1995). Comparison of standards for assessing patients' capacities to make treatment decisions. American Journal of Psychiatry, 152(7), 1033-1037.

Hall, M. A., Camacho, F., Dugan, E., \& Balkrishnan, R. (2002). Trust in the medical profession: conceptual and measurement issues. Health services research, 37(5), 1419-1439. doi:10.1111/1475-6773.01070 
Hamilton, L. D., Van Dam, D., \& Wassersug, R. J. (2016). The perspective of prostate cancer patients and patients' partners on the psychological burden of androgen deprivation and the dyadic adjustment of prostate cancer couples. Psycho-Oncology, 25(7), 823-831.

Hare, J., Pratt, C., \& Nelson, C. (1992). Agreement between patients and their self-selected surrogates on difficult medical decisions. Archives of Internal Medicine, 152(5), 1049-1054.

Hartley, C. A., \& Phelps, E. A. (2012). Anxiety and decision-making. Biological psychiatry, 72(2), 113118. doi:10.1016/j.biopsych.2011.12.027

Helsper, E. J., \& Whitty, M. T. (2010). Netiquette within married couples: Agreement about acceptable online behavior and surveillance between partners. Computers in Human Behavior, 26(5), 916 926. doi:10.1016/j.chb.2010.02.006

Henningsgaard, J. M., \& Arnau, R. C. (2008). Relationships between religiosity, spirituality, and personality: A multivariate analysis. Personality and Individual Differences, 45(8), 703-708. doi:10.1016/j.paid.2008.07.004

Hindmarch, T., Hotopf, M., \& Owen, G. S. (2013). Depression and decision-making capacity for treatment or research: a systematic review. BMC medical ethics, 14(1), 54. doi:10.1186/14726939-14-54

Jahn, D. R., Cukrowicz, K. C., Linton, K., \& Prabhu, F. (2011). The mediating effect of perceived burdensomeness on the relation between depressive symptoms and suicide ideation in a community sample of older adults. Aging \& Mental Health, 15(2), 214-220. doi:10.1080/13607863.2010.501064

Johnson, S. K., Bautista, C. A., Hong, S. Y., Weissfeld, L., \& White, D. B. (2011). An empirical study of surrogates' preferred level of control over value-laden life support decisions in intensive care units. American journal of respiratory and critical care medicine, 183(7), 915-921. 
Johns Hopkins Medicine (2020). Common Surgical Procedures.

https://www.hopkinsmedicine.org/health/treatment-tests-and-therapies/common-surgicalprocedures

Joiner, T. E., Pettit, J. W., Walker, R. L., Voelz, Z. R., Cruz, J., Rudd, M. D., \& Lester, D. (2002). Perceived burdensomeness and suicidality: Two studies on the suicide notes of those attempting and those completing suicide. Journal of Social and Clinical Psychology, 21(5), 531-545. doi:10.1521/jscp.21.5.531.22624

Kahneman, D. \& Tversky, A. (2013). Choices, values, and frames. In Handbook of the fundamentals of financial decision making: Part I (pp. 269-278).

Kanzler, K. E., Bryan, C. J., McGeary, D. D., \& Morrow, C. E. (2012). Suicidal ideation and perceived burdensomeness in patients with chronic pain. Pain Practice, 12(8), 602-609. doi:10.1111/j.1533-2500.2012.00542.x

Kaplan, R. M. (2004). Shared medical decision making: a new tool for preventive medicine. American journal of preventive medicine, 26(1), 81-83. doi:10.1016/j.amepre.2003.09.022

Kaplan, R. M., \& Frosch, D. L. (2005). Decision making in medicine and health care. Annual Review of Clinical Psychology, 1, 525-556.

Keren, G. (1991). Calibration and probability judgements: Conceptual and methodological issues. Acta Psychologica, 77(3), 217-273.

Klest, B., \& Philippon, O. (2016). Trust in the medical profession and patient attachment style. Psychology, Health \& Medicine, 21(7), 863-870. doi:10.1080/13548506.2015.1120328

Koenig, H. G., \& Büssing, A. (2010). The Duke University Religion Index (DUREL): a five-item measure for use in epidemological studies. Religions, 1(1), 78-85. 
Kon, A. A., Davidson, J. E., Morrison, W., Danis, M., \& White, D. B. (2016). Shared decision making in intensive care units: an American College of Critical Care Medicine and American Thoracic Society policy statement. Critical Care Medicine, 44(1), 188.

Krantz, D. S., Baum, A., \& Wideman, M. V. (1980). Assessment of preferences for self-treatment and information in health care. Journal of personality and social psychology, 39(5), 977. doi:10.1037/0022-3514.39.5.977

Kumar, R., Korthuis, P. T., Saha, S., Chander, G., Sharp, V., Cohn, J., ... \& Beach, M. C. (2010). Decision-making role preferences among patients with HIV: associations with patient and provider characteristics and communication behaviors. Journal of General Internal Medicine, $25(6), 517-523$.

Lamm, C., Batson, C. D., \& Decety, J. (2007). The Neural Substrate of Human Empathy: Effects of Perspective-taking and Cognitive Appraisal. Journal of Cognitive Neuroscience, 19(1), 42-58. doi:10.1162/jocn.2007.19.1.42

Lauriola, M., \& Levin, I. P. (2001). Personality traits and risky decision-making in a controlled experimental task: an exploratory study. Personality and Individual Differences, 31(2), 215-226. doi:10.1016/s0191-8869(00)00130-6

Lee, C., Ayers, S. L., \& Kronenfeld, J. J. (2009). The association between perceived provider discrimination, health care utilization, and health status in racial and ethnic minorities. Ethnicity \& Disease, 19(3), 330.

Lee, S. A. (2020). Coronavirus Anxiety Scale: A brief mental health screener for COVID-19 related anxiety. Death Studies, 44(7), 393-401.

Leventhal, H., \& Patrick-Miller, L. (1993). Emotion and illness: The mind is in the body. In M. Lewis \& J. M. Haviland (Eds.), Handbook of emotions (p. 365-379). Guilford Press. 
Li, L. L. M., Cheong, K. Y. P., Yaw, L. K., \& Liu, E. H. C. (2007). The accuracy of surrogate decisions in intensive care vignettes. Anaesthesia and Intensive Care, 35(1), 46-51. doi:10.1177/0310057x0703500105

Loewenstein, G. (2005). Hot-cold empathy gaps and medical decision making. Health psychology, 24(4S), S49. S49-S56. doi:10.1037/0278-6133.24.4.s49

Loewenstein, G. F., Weber, E. U., Hsee, C. K., \& Welch, N. (2001). Risk as feelings. Psychological Bulletin, 127(2), 267.

Lord, K., Livingston, G., \& Cooper, C. (2015). A systematic review of barriers and facilitators to and interventions for proxy decision-making by family carers of people with dementia. International Psychogeriatrics, 27(8), 1301-1312. doi:10.1017/s1041610215000411

Lu, Jingyi, Xiaofei Xie, and Jingzhe Xu. "Desirability or feasibility: Self-other decision-making differences." Personality and Social Psychology Bulletin 39.2 (2013): 144-155. doi:10.1177/0146167212470146

Mack, J. W., Paulk, M. E., Viswanath, K., \& Prigerson, H. G. (2010). Racial Disparities in the Outcomes of Communication on Medical Care Received Near Death. Archives of Internal Medicine, 170(17). doi:10.1001/archinternmed.2010.322

Maddox, C., Halsall, D., Hall, J., \& Tully, M. P. (2016). Factors influencing nurse and pharmacist willingness to take or not take responsibility for non-medical prescribing. Research in Social and Administrative Pharmacy, 12(1), 41-55. doi:10.1016/j.sapharm.2015.04.001

Maguire, P., Faulkner, A., Booth, K., Elliott, C., \& Hillier, V. (1996). Helping cancer patients disclose their concerns. European Journal of Cancer, 32(1), 78-81. doi:10.1016/0959-8049(95)00527-7 
Maner, J. K., Richey, J. A., Cromer, K., Mallott, M., Lejuez, C. W., Joiner, T. E., \& Schmidt, N. B. (2007). Dispositional anxiety and risk-avoidant decision-making. Personality and Individual Differences, 42(4), 665-675.

Mansell, D., Poses, R. M., Kazis, L., \& Duefield, C. A. (2000). Clinical factors that influence patients' desire for participation in decisions about illness. Archives of Internal Medicine, 160(19), 29912996.

Marbella, A. M., Desbiens, N. A., Mueller-Rizner, N., \& Layde, P. M. (1998). Surrogates' agreement with patients' resuscitation preferences: effect of age, relationship, and SUPPORT intervention. Journal of Critical Care, 13(3), 140-145.

Margrett, J. A., \& Marsiske, M. (2002). Gender differences in older adults' everyday cognitive collaboration. International Journal of Behavioral Development, 26(1), 45-59. doi:10.1080/01650250143000319

Marks, M. A., \& Arkes, H. R. (2008). Patient and surrogate disagreement in end-of-life decisions: can surrogates accurately predict patients' preferences? Medical Decision Making, 28(4), 524-531.

McCroskey, J. C., Richmond, V. P., \& Daly, J. A. (1975). The development of a measure of perceived homophily in interpersonal communication. Human Communication Research, 1(4), 323-332. doi:10.1111/j.1468-2958.1975.tb00281.x

McDade-Montez, E., Watson, D., \& Beer, A. (2013). Similarity, agreement, and assumed similarity in proxy end-of-life decision making. Families, Systems, \& Health, 31(4), 366. doi: $10.1037 / \mathrm{a} 0033372$

Meeker, M. A. (2004). Family surrogate decision making at the end of life: seeing them through with care and respect. Qualitative Health Research, 14(2), 204-225. 
Mezey, M., Kluger, M., Maislin, G., \& Mittelman, M. (1996). Life-sustaining treatment decisions by spouses of patients with Alzheimer's disease. Journal of the American Geriatrics Society, 44(2), 144-150.

Muni, S., Engelberg, R. A., Treece, P. D., Dotolo, D., \& Curtis, J. R. (2011). The Influence of Race/Ethnicity and Socioeconomic Status on End-of-Life Care in the ICU. Chest, 139(5), 10251033. doi:10.1378/chest.10-3011

Murphy, F. C., Rubinsztein, J. S., Michael, A., Rogers, R. D., Robbins, T. W., Paykel, E. S., \& Sahakian, B. J. (2001). Decision-making cognition in mania and depression. Psychological medicine, 31(4), 679-693. doi:10.1017/s0033291701003804

Murray, S. L. (1999). The quest for conviction: Motivated cognition in romantic relationships. Psychological Inquiry, 10(1), 23-34.

Nahm, E. S., Resnick, B., Orwig, D., Magaziner, J., Bellantoni, M., Sterling, R., \& Brennan, P. F. (2012). A theory-based online hip fracture resource center for caregivers: effects on dyads. Nursing research, 61(6), 413. doi:10.1097/nnr.0b013e318270712a

Nelson, J. E., Mulkerin, C. M., Adams, L. L., \& Pronovost, P. J. (2006). Improving comfort and communication in the ICU: a practical new tool for palliative care performance measurement and feedback. BMJ Quality \& Safety, 15(4), 264-271. doi:10.1136/qshc.2005.017707

Nowak, K. L., \& Rauh, C. (2005). The influence of the avatar on online perceptions of anthropomorphism, androgyny, credibility, homophily, and attraction. Journal of ComputerMediated Communication, 11(1), 153-178. doi:10.1111/j.1083-6101.2006.tb00308.x

O’Brien, E., Konrath, S. H., Gruhn, D., \& Hagen, A. L. (2012). Empathic Concern and Perspective Taking: Linear and Quadratic Effects of Age Across the Adult Life Span. The Journals of 
Gerontology Series B: Psychological Sciences and Social Sciences, 68(2), 168-175. doi:10.1093/geronb/gbs055

Oh, A. Y., Davis, T., Dwyer, L. A., Hennessy, E., Li, T., Yaroch, A. L., \& Nebeling, L. C. (2017). Recruitment, enrollment, and response of parent-adolescent dyads in the FLASHE study. American journal of preventive medicine, 52(6), 849-855. doi:10.1016/j.amepre.2016.11.028

Paulus, M. P., \& Angela, J. Y. (2012). Emotion and decision-making: affect-driven belief systems in anxiety and depression. Trends in cognitive sciences, 16(9), 476-483. doi:10.1016/j.tics.2012.07.009

Pattison, N. (2020). End-of-life decisions and care in the midst of a global coronavirus (COVID-19) pandemic. Intensive \& Critical Care Nursing, 58, 102862.

Pellegrino, E. D. (2000). Decisions to withdraw life-sustaining treatment: a moral algorithm. JAMA, 283(8), 1065-1067. doi:10.1001/jama.283.8.1065

Petersen, S., Sherman-Slate, E., Straub, J. L., Schwartz, R. C., Frost, H., \& Damjanov, N. (2003). Relationship of depression and anxiety to cancer patients' medical decisionmaking. Psychological reports, 93(2), 323-334.

Pham, M. T. (2007). Emotion and rationality: A critical review and interpretation of empirical evidence. Review of general psychology, 11(2), 155-178.

Phelps, A. C., Maciejewski, P. K., Nilsson, M., Balboni, T. A., Wright, A. A., Paulk, M. E., ... \& Prigerson, H. G. (2009). Religious coping and use of intensive life-prolonging care near death in patients with advanced cancer. JAMA, 301(11), 1140-1147.

Pochard, F., Azoulay, E., Chevret, S., Lemaire, F., Hubert, P., Canoui, P., \& Schlemmer, B. (2001). Symptoms of anxiety and depression in family members of intensive care unit patients: ethical 
hypothesis regarding decision-making capacity. Critical care medicine, 29(10), 1893-1897. doi:10.1097/00003246-200110000-00007

Polman, E. (2012). Self-other decision making and loss aversion. Organizational Behavior and Human Decision Processes, 119(2), 141-150. doi:10.1016/j.obhdp.2012.06.005

Powell, T. (1999). Extubating Mrs. K: Psychological aspects of surrogate decision making. The Journal of Law, Medicine \& Ethics, 27(1), 81-86. doi:10.1111/j.1748-720x.1999.tb01439.x

Power, T. E., Swartzman, L. C., \& Robinson, J. W. (2011). Cognitive-emotional decision making (CEDM): A framework of patient medical decision making. Patient Education and Counseling, 83(2), 163-169. doi:10.1016/j.pec.2010.05.021

Pruchno, R. A., Lemay Jr, E. P., Feild, L., \& Levinsky, N. G. (2005). Spouse as health care proxy for dialysis patients: whose preferences matter?. The Gerontologist, 45(6), 812-819. doi:10.1093/geront/45.6.812

Radloff, L. S. (1977). The CES-D scale: A self-report depression scale for research in the general population. Applied Psychological Measurement, 1(3), 385-401.

Ranney, M. L., Griffeth, V., \& Jha, A. K. (2020). Critical supply shortages - the need for ventilators and personal protective equipment during the Covid-19 pandemic. New England Journal of Medicine, 382(18), e41.

Rid, A., \& Wendler, D. (2010). Can we improve treatment decision-making for incapacitated patients?. Hastings Center Report, 40(5), 36-45.

Rittenour, C. E., \& Martin, M. M. (2008). Convergent validity of the communication based emotional support scale. Communication Studies, 59(3), 235-241. 
Robinson, A., \& Thomson, R. (2001). Variability in patient preferences for participating in medical decision making: implication for the use of decision support tools. Quality and Safety in Health Care, 10(Supplement 1), i34-i38. doi:10.1136/qhc.0100034

Say, R., Murtagh, M., \& Thomson, R. (2006). Patients' preference for involvement in medical decision making: a narrative review. Patient education and counseling, 60(2), 102-114. doi:10.1016/j.pec.2005.02.003

Schenker, Y., Crowley-Matoka, M., Dohan, D., Tiver, G. A., Arnold, R. M., \& White, D. B. (2012). I don't want to be the one saying 'we should just let him die': intrapersonal tensions experienced by surrogate decision makers in the ICU. Journal of General Internal Medicine, 27(12), $1657-$ 1665.

Schonwetter, R. S., Walker, R. M., Solomon, M., Indurkhya, A., \& Robinson, B. E. (1996). Life values, resuscitation preferences, and the applicability of living wills in an older population. Journal of the American geriatrics society, 44(8), 954-958.

Schneider, C., \& Schneider, D. (1998). The practice of autonomy: patients, doctors, and medical decisions. Oxford University Press on Demand.

Scheunemann, L. P., \& White, D. B. (2011). The Ethics and Reality of Rationing in Medicine. Chest, 140(6), 1625-1632. doi:10.1378/chest.11-0622

Schwarz, N., \& Clore, G.L. (1996). Feelings and phenomenal experiences. In E.T. Higgins \& A. Kruglanski (Eds.), Social psychology: Handbook of basic principles (pp. 433 \pm 465$)$. New York: Guilford.

Selph, R. B., Shiang, J., Engelberg, R., Curtis, J. R., \& White, D. B. (2008). Empathy and life support decisions in intensive care units. Journal of general internal medicine, 23(9), 1311. doi:10.1007/s11606-008-0643-8 
Shalowitz, D. I., Garrett-Mayer, E., \& Wendler, D. (2006). The Accuracy of Surrogate Decision Makers. Archives of Internal Medicine, 166(5), 493. doi:10.1001/archinte.166.5.493

Shay, L. A., \& Lafata, J. E. (2014). Where Is the Evidence? A Systematic Review of Shared Decision Making and Patient Outcomes. Medical Decision Making, 35(1), 114-131. doi:10.1177/0272989x14551638

Simmons, L. A. (2007). Self-perceived Burden in Cancer Patients. Cancer Nursing, 30(5), 405-411. doi:10.1097/01.ncc.0000290816.37442.af

Sitkin, S. B., \& Weingart, L. R. (1995). Determinants of Risky Decision-Making Behavior: A Test of the Mediating Role of Risk Perceptions and Propensity. Academy of Management Journal, 38(6), 1573-1592. doi:10.5465/256844

Somerville, L. H., Kim, H., Johnstone, T., Alexander, A. L., \& Whalen, P. J. (2004). Human amygdala responses during presentation of happy and neutral faces: correlations with state anxiety. Biological psychiatry, 55(9), 897-903. doi:10.1016/j.biopsych.2004.01.007

Spalding, R. (2020). Accuracy in Surrogate End-of-Life Medical Decision-Making: A Critical Review. Applied Psychology: Health and Well-Being. doi: 10.1111/aphw.12221

Spalding, R., \& Carpenter, B. (2018). Examining the Intergenerational Stake Hypothesis in Grandparent-Grandchild Dyads. The International Journal of Aging and Human Development, 89(2), 172-186. doi:10.1177/0091415018780008

Spalding, R., \& Edelstein, B. (2020). Factors predicting collaborative willingness of surrogates making medical decisions on the Physician Order for Scope of Treatment (POST). Aging \& Mental Health, 24(9), 1543-1552. 
Stone, E. R., \& Allgaier, L. (2008). A social values analysis of self-other differences in decision making involving risk. Basic and Applied Social Psychology, 30(2), 114-129. doi:10.1080/01973530802208832

Stone, E. R., YoonSun, C., Bruine de Bruin, W., \& Mandel, D. R. (2013). I can take the risk, but you should be safe: Self-other differences in situations involving physical safety. Judgment and Decision making, 8(3), 250-267.

St Ledger, U., Begley, A., Reid, J., Prior, L., McAuley, D., \& Blackwood, B. (2013). Moral distress in end-of-life care in the intensive care unit. Journal of Advanced Nursing, 69(8), 1869-1880.

Sung, V. W., Raker, C. A., Myers, D. L., \& Clark, M. A. (2010). Treatment decision-making and information-seeking preferences in women with pelvic floor disorders. International urogynecology journal, 21(9), 1071-1078.

Swindell, J. S., McGuire, A. L., \& Halpern, S. D. (2010). Beneficent persuasion: techniques and ethical guidelines to improve patients' decisions. The Annals of Family Medicine, 8(3), 260-264.

Tang, F., Liang, J., Zhang, H., Kelifa, M. M., He, Q., \& Wang, P. (2020). COVID-19 related depression and anxiety among quarantined respondents. Psychology \& Health, 1-15.

Tejwani, V., Bannon, M., Seggura, L., Serrano, S., \& Wu, Y. (2013). Issues surrounding end-of-life decision-making. Patient Preferences and Adherence, 7, 771. doi:10.2147/ppa.s48135

Tomlinson, T., Howe, K., Notman, M., \& Rossmiller, D. (1990). An empirical study of proxy consent for elderly persons. The Gerontologist, 30(1), 54-64. doi:10.1093/geront/30.1.54

Torke, A. M., Alexander, G. C., \& Lantos, J. (2008). Substituted judgment: the limitations of autonomy in surrogate decision making. Journal of General Internal Medicine, 23(9), 1514-1517. 
Torke, A. M., Fitchett, G., Maiko, S., Burke, E. S., Slaven, J. E., Watson, B. N., \& Monahan, P. O. (2020). The Association of Surrogate Decision Makers' Religious and Spiritual Beliefs With End-of-Life Decisions. Journal of Pain and Symptom Management, 59(2), 261-269.

Torke, A. M., Sachs, G. A., Helft, P. R., Montz, K., Hui, S. L., Slaven, J. E., \& Callahan, C. M. (2014). Scope and outcomes of surrogate decision making among hospitalized older adults. JAMA internal medicine, 174(3), 370-377. doi:10.1001/jamainternmed.2013.13315

Thom, D. H., Hall, M. A., \& Pawlson, L. G. (2004). Measuring patients' trust in physicians when assessing quality of care. Health affairs, 23(4), 124-132. doi:10.1377/hlthaff.23.4.124

Tilden, V. P., Tolle, S. W., Nelson, C. A., Thompson, M., \& Eggman, S. C. (1999). Family decision making in foregoing life-extending treatments. Journal of Family Nursing, 5(4), 426-442.

Tomlinson, T., Howe, K., Notman, M., \& Rossmiller, D. (1990). An empirical study of proxy consent for elderly persons. The Gerontologist, 30(1), 54-64. doi:10.1093/geront/30.1.54

Trachtenberg, F., Dugan, E., \& Hall, M. A. (2005). How patients' trust relates to their involvement in medical care. Journal of Family Practice, 54(4), 344-354.

Tunney, R. J., \& Ziegler, F. V. (2015a). Toward a Psychology of Surrogate Decision Making. Perspectives on Psychological Science, 10(6), 880-885. doi:10.1177/1745691615598508

Tunney, R. J., \& Ziegler, F. V. (2015b). Surrogate utility estimation by long-term partners and unfamiliar dyads. Frontiers in psychology, 6, 315.

Ubel, P. A., Loewenstein, G., Schwarz, N., \& Smith, D. (2005). Misimagining the unimaginable: the disability paradox and health care decision making. Health Psychology, 24(4S), S57.

Uhlmann, R. F., Pearlman, R. A., \& Cain, K. C. (1988). Physicians' and spouses' predictions of elderly patients' resuscitation preferences. Journal of Gerontology, 43(5), M115-M121. 
Van Dam, N. T., \& Earleywine, M. (2011). Validation of the Center for Epidemiologic Studies Depression Scale_-Revised (CESD-R): Pragmatic depression assessment in the general population. Psychiatry Research, 186(1), 128-132.

Van der Heide, I., Wang, J., Droomers, M., Spreeuwenberg, P., Rademakers, J., \& Uiters, E. (2013). The Relationship Between Health, Education, and Health Literacy: Results From the Dutch Adult Literacy and Life Skills Survey. Journal of Health Communication, 18(sup1), 172-184. doi:10.1080/10810730.2013.825668

Van Orden, K. A., Lynam, M. E., Hollar, D., \& Joiner, T. E. (2006). Perceived burdensomeness as an indicator of suicidal symptoms. Cognitive Therapy and Research, 30(4), 457-467.

Van Voorhis, C. R., \& Morgan, B. L. (2007). Understanding power and rules of thumb for determining sample sizes. Tutorials in Quantitative Methods for Psychology, 3(2), 43-50. doi:10.20982/tqmp.03.2.p043

Vick, S., \& Scott, A. (1998). Agency in health care. Examining patients' preferences for attributes of the doctor-patient relationship. Journal of health economics, 17(5), 587-605.

Vig, E. K., Starks, H., Taylor, J. S., Hopley, E. K., \& Fryer-Edwards, K. (2007). Surviving Surrogate Decision-Making: What Helps and Hampers the Experience of Making Medical Decisions for Others. Journal of General Internal Medicine, 22(9), 1274-1279. doi:10.1007/s11606-007-0252$\mathrm{y}$

Volandes, A. E., Ariza, M., Abbo, E. D., \& Paasche-Orlow, M. (2008). Overcoming Educational Barriers for Advance Care Planning in Latinos with Video Images. Journal of Palliative Medicine, 11(5), 700-706. doi:10.1089/jpm.2007.0172 
Volandes, A. E., Pasche-Orlow, M., Gillick, M. R., Cook, E. F., Shaykevich, S., Abbo, E. D., \& Lehmann, L. (2008). Health Literacy not Race Predicts End-of-Life Care Preferences. Journal of Palliative Medicine, 11(5), 754-762. doi:10.1089/jpm.2007.0224

Wager, T. D., Davidson, M. L., Hughes, B. L., Lindquist, M. A., \& Ochsner, K. N. (2008). Prefrontalsubcortical pathways mediating successful emotion regulation. Neuron, 59(6), 1037-1050.

Weber, K., Johnson, A., \& Corrigan, M. (2004). Communcating emotional support and its relationship to feelings of being understood, trust, and self-disclosure. Communication research reports, 21(3), 316-323.

Wendler, D., \& Rid, A. (2011). Systematic review: the effect on surrogates of making treatment decisions for others. Annals of internal medicine, 154(5), 336-346. doi:10.7326/0003-4819-1545-201103010-00008

Weston, S. J., Hill, P. L., \& Jackson, J. J. (2014). Personality Traits Predict the Onset of Disease. Social Psychological and Personality Science, 6(3), 309-317. doi:10.1177/1948550614553248

White, D. B., Cua, S. M., Walk, R., Pollice, L., Weissfeld, L., Hong, S., \& Arnold, R. M. (2012). Nurseled intervention to improve surrogate decision making for patients with advanced critical illness. American Journal of Critical Care, 21(6), 396-409.

White, D. B., \& Arnold, R. M. (2011). The Evolution of Advance Directives. Journal of the American Medical Association, 306(13), 1485. doi:10.1001/jama.2011.1430

Winter, L., \& Parks, S. M. (2012). The reluctance to burden others as a value in end-of-life decision making: a source of inaccuracy in substituted judgment. Journal of health psychology, 17(2), 179-188. doi:10.1177/1359105311414956

Winter, L. (2013). Patient values and preferences for end-of-life treatments: are values better predictors than a living will? Journal of Palliative Medicine, 16(4), 362-368. doi:10.1089/jpm.2012.030 
Yarnell, C. J., Fu, L., Manuel, D., Tanuseputro, P., Stukel, T., Pinto, R., \& Fowler, R. A. (2017). Association Between Immigrant Status and End-of-Life Care in Ontario, Canada. Journal of the American Medical Association, 318(15), 1479. doi:10.1001/jama.2017.14418

Zweibel, N. R., \& Cassel, C. K. (1989). Treatment choices at the end of life: a comparison of decisions by older patients and their physician-selected proxies. The Gerontologist, 29(5), 615-621. doi:10.1093/geront/29.5.615 
Page intentionally left blank. 
Appendix A

\section{Demographic Questionnaire}

Name:

Age:

Sex: (choose one)

Male Female Transgender Female Transgender Male Gender Non-conforming

Years of Education:

Marital Status: (choose one)

Single Married/Committed Relationship Separated Divorced Widowed

Ethnicity: (choose all that apply)

Caucasian/White

African American/Black

Asian American

Hispanic/Latino

Pacific Islander

Native American (American Indian/Alaskan Native)

In what geographic region of the United States do you live?

Northeast Southeast Midwest Southwest Northwest

Do you have health insurance?

Yes No

How would you rate your physical health, overall?

Poor Fair Good Very good Excellent

Have you heard of COVID-19 (coronavirus)?

Yes No

To what extent are you worried about COVID-19?

Not at all (1) $234 \quad$ Moderately (5) $6789 \quad$ Very much (10)

In this study, both you and another individual from your life will be participating. What is your relationship to this person? (choose one)

Spouse/partner Sibling Parent Adult child Close friend Other family member 
To what extent have you talked with this person about end-of-life decisions, including personal preferences?

Not at all A little Moderately Very much

For this study, it is important that you do not discuss the contents of this survey with this person.

By typing your full name in the space provided, you agree that you will not discuss any portion of this survey with this person: 


\section{Appendix B}

Decision Task (from Hare et al., 1992)

Surrogate Instructions: When reading the following vignettes, please imagine the person you identified on the demographic questionnaire is the patient. Also imagine that you are formally serving in a surrogate decision-making role where a healthcare provider is asking you to give instructions. When making these decisions, please make the decision that you think the patient would choose.

Note: use of the word "you" and "the patient" in the vignettes will vary based on survey version (patient or surrogate), as indicated by italics. Respondents' choice options for each decision are indicated in bold text.

\section{$\underline{\text { Part A: Ventilation }}$}

Sometimes when a patient cannot breathe on his/her own, a tube is placed down the windpipe of the patient and attached to a breathing machine, which can either totally or partially take over breathing for the patient. The following case is about a woman who cannot breathe on her own.

Mrs K. is a woman the patient's/your age who has recently suffered a major stroke, leaving her in a coma and unable to breathe without a machine. After a few weeks, the doctor tells you that it is unlikely that Mrs K. will come out of the coma and that no one can be certain what her level of functioning would be if she ever did come out of the coma. What if this were the patient/you and the doctor asked you whether the breathing machine should be removed or continued? What would you say? (Remove/Continue)

To what extent do you feel you understand the costs and benefits associated with this treatment? Not at all A little Somewhat Moderately Very much

To what extent do you feel that your family and friends find this treatment acceptable?

Not at all A little Somewhat Moderately Very much

To what extent do you feel confident in this decision?

Not at all A little Somewhat Moderately Very much

\section{$\underline{\text { Part B: Resuscitation }}$}

If a patient's heart or breathing stops while in the hospital, an emergency team will be called to try to get the heart and lungs started again. This is called CPR (resuscitation).

Again, think of the first case. Suppose the doctor wanted to know whether to try to resuscitate the patient/you if their/your heart stopped beating? What would you say? (Do not attempt CPR/Attempt CPR) 
To what extent do you feel you understand the costs and benefits associated with this treatment?

Not at all A little Somewhat Moderately Very much

To what extent do you feel that your family and friends find this treatment acceptable?

Not at all A little Somewhat Moderately Very much

To what extent do you feel confident in this decision?

Not at all A little Somewhat Moderately Very much

\section{$\underline{\text { Part C: Tube feeding }}$}

A patient who cannot eat can be fed through a nasogastric (NG) tube. This tube is placed down the nose and through the esophagus into the stomach. High-energy liquid foods are delivered down the tube. Often the patient has some diarrhea for the first week or two because of the different type of food that is being digested. Other types of artificial feeding methods that can be used are intravenous lines or a tube placed through the belly wall into the stomach.

Think of Mrs K. again. Because Mrs K. cannot eat or drink, she must be given artificial nutrition and hydration to keep her alive. A feeding tube may keep her alive perhaps for many more years. If this were the patient/you would you or would you not have the feeding tube placed? (No/Yes)

To what extent do you feel you understand the costs and benefits associated with this treatment? Not at all A little Somewhat Moderately Very much

To what extent do you feel that your family and friends find this treatment acceptable?

Not at all A little Somewhat Moderately Very much

To what extent do you feel confident in this decision?

Not at all A little Somewhat Moderately Very much

\section{Part D: Chemotherapy}

Mr. L. is a man the patient's/your age who has been diagnosed as having a type of cancer that probably cannot be cured. Because of mental confusion, Mr L. cannot make medical decisions on his own. His doctor recommends to you that chemotherapy be started. The doctor explains that the chances of curing Mr L. are very small but that the chemotherapy may help him live longer. You are also told about the side effects of chemotherapy, which can make a patient very ill. What if this were the patient/you? What would you tell the doctor to do? (Do not begin chemotherapy/Begin chemotherapy)

To what extent do you feel you understand the costs and benefits associated with this treatment? Not at all A little Somewhat Moderately Very much

To what extent do you feel that your family and friends find this treatment acceptable? 
Not at all A little Somewhat Moderately Very much

To what extent do you feel confident in this decision?

Not at all A little Somewhat Moderately Very much

Part E: Amputation

Mr. S. is a man the patient's/your age who has for many months been unable to make medical decisions for himself because he has become mentally confused. Because of diabetes, he has developed gangrene, or blood poisoning, in his leg. The doctor recommends that unless Mr. S. has his leg removed, he will almost certainly die in a very short time. If the leg is not amputated, medications can be given to control the pain, but he would almost surely die in a matter of days from the blood poisoning. What if this were the patient/you? What would you tell the doctor to do? (Do not amputate/Amputate)

To what extent do you feel you understand the costs and benefits associated with this treatment? Not at all A little Somewhat Moderately Very much

To what extent do you feel that your family and friends find this treatment acceptable?

Not at all A little Somewhat Moderately Very much

To what extent do you feel confident in this decision?

Not at all A little Somewhat Moderately Very much

Part F: Coronary Artery Disease- Bypass Surgery

Bypass surgery helps improve blood flow to the heart in people with severe heart disease. Bypass surgery might improve your chances of living a longer life. Most of the time, bypass surgery is open-chest surgery. It can ease symptoms, such as chest pain and shortness of breath. For some people, this procedure can improve heart function and reduce the risk of dying of heart disease. Although complications from bypass surgery are uncommon, risk is a part of every surgical procedure. Potential risks include wound infection and bleeding, adverse reactions to anesthesia, fever, pain, stroke, heart attack, or even death. Bypass surgery is not a cure for heart disease. The surgery doesn't change the way arteries harden or narrow because of heart disease. Even after surgery, you can still get new places in your arteries that are narrowed, so you will still need to continue medicines and lifestyle changes to give you the best chance of living a longer, healthier life.

Suppose that the patient/you has started experiencing some symptoms of chest pressure and shortness of breath at times. Your doctor gives you some tests and diagnoses you/the patient with severe heart disease and says that you should consider bypass surgery as a treatment option. Would you choose for yourself/the patient to have the surgery? (Have bypass/Do not have bypass)

To what extent do you feel you understand the costs and benefits associated with this treatment? 
Not at all A little Somewhat Moderately Very much

To what extent do you feel that your family and friends find this treatment acceptable?

Not at all A little Somewhat Moderately Very much

To what extent do you feel confident in this decision?

Not at all A little Somewhat Moderately Very much

Part G: Chronic Kidney Disease_-Dialysis Treatment

Chronic kidney disease (CKD) is a long-term health problem where the kidneys slowly stop working. Over time, the damaged kidneys may stop working altogether. When the kidneys work less than about $10-15 \%$ of their normal rate, the kidney disease is described as established kidney disease (EKD). There is no cure for people with established kidney disease. Once people have established kidney disease, they have it for the rest of their life.

Dialysis is a treatment for established kidney disease that uses equipment to clean your blood and do some of the work that healthy kidneys do. Patients usually receive three dialysis treatments per week, and each treatment session usually takes at least 3 hours to complete. Dialysis does about $10 \%$ of the work of healthy kidneys and improves some of the symptoms of kidney disease, but does not cure the chronic kidney disease. Failing kidneys will keep getting worse. Most people with established kidney failure who have dialysis treatments live longer than people who do not. Without treatment, the average life expectancy for a person diagnosed with established kidney failure is 6 months, whereas the average life expectancy of a person receiving dialysis treatment is about 4 years. Once a person begins dialysis treatment, they will need to have dialysis for the rest of their lives, or until they have a successful kidney transplant.

There are some common problems people may get when they have dialysis including fatigue, dizziness, and adjusting to the dialysis routine. All people having dialysis are seen by a specialist team at hospital, and in their homes, to help make the changes needed to their food, drink, and medicines.

Suppose that the patient/you has a diagnosis of established kidney disease. The doctor presents dialysis treatment as the next treatment option that you/the patient could seek at this time. Would you choose for yourself/the patient to begin dialysis treatment? (Begin dialysis/Do not begin dialysis)

To what extent do you feel you understand the costs and benefits associated with this treatment? Not at all A little Somewhat Moderately Very much

To what extent do you feel that your family and friends find this treatment acceptable?

Not at all A little Somewhat Moderately Very much

To what extent do you feel confident in this decision?

Not at all A little Somewhat Moderately Very much 


\section{Appendix C}

\section{Trust in the Medical Profession Scale (TIMPS; Hall et al., 2002)}

Please use the below scale to indicate how much you agree with each statement.

$\begin{array}{ccccc}1 & 2 & 3 & 4 & 5 \\ \text { (strongly disagree) } & & \text { (neither agree nor disagree) } & & \text { (strongly agree) }\end{array}$

1. Doctors in general care about their patients' health just as much or more than their patients do.

2. Sometimes doctors care more about what is convenient for them than about their patients' medical needs.

3. Doctors are extremely thorough and careful.

4. You completely trust doctors' decisions about which medical treatments are best.

5. Doctors are totally honest in telling their patients about all of the different treatment options available for their conditions.

6. Doctors think only about what is best for their patients.

7. Sometimes doctors do not pay full attention to what patients are trying to tell them.

8. Doctors always use their very best skill and effort on behalf of their patients.

9. You have no worries about putting your life in the hands of doctors.

10. A doctor would never mislead you about anything.

11. All in all, you trust doctors completely. 


\section{Appendix D}

\section{Communication-Based Emotional Support Scale (CBESS; Weber \& Patterson, 1996)}

Please use the below scale to indicate how much each statement is true of you, in general, with regard to your partner in this study.

$\begin{array}{ccccc}1 & 2 & 3 & 4 & 5 \\ \text { (almost never true) (rarely true) } & \text { (occasionally true) (often true) } & \text { (almost always true) }\end{array}$

1. My partner helps me work through my thoughts and feelings about major life decisions (e.g., career choices).

2. My partner patiently and sensitively listens to me "let off steam" about an outside problem that I am having.

3. When I tell my partner about a problem I am having, they don't seem to be paying attention.

4. My partner helps me cope with problems concerning other friends or family members.

5. My partner avoids me when I am depressed.

6. My partner is good listeners when I am upset.

7. When I am feeling down, my partner can say and do supportive things.

8. When I want to talk to someone about something that is bothering me, my partner seems to have something else to do.

9. My partner shows genuine concern for my problems.

10. My partner gives me good advice when I ask for it.

11. My partner makes it easy to discuss my personal feelings.

12. My partner listens to my side of the story even when they think that I am wrong.

13. My partner makes an effort to make me feel better when I am depressed. 
Appendix E

Center for Epidemiological Studies Depression Scale-Revised (CESD-R; Eaton et al., 2004)

Please use the below scale to indicate how frequently you experienced each of the following symptoms over the past two weeks.

$\begin{array}{ccccc}1 & 2 & 3 & 4 & 5 \\ \text { (not at all or }<1 \text { day }) & (1-2 \text { days }) & (3-4 \text { days }) & (5-7 \text { days }) & \text { (nearly every day) }\end{array}$

1. My appetite was poor

2. I could not shake off the blues.

3. I had trouble keeping my mind on what I was doing.

4. I felt depressed.

5. My sleep was restless.

6. I felt sad.

7. I could not get going.

8. Nothing made me happy.

9. I felt like a bad person.

10. I lost interest in my usual activities.

11. I slept much more than usual.

12. I felt like I was moving too slowly.

13. I felt fidgety.

14. I wished I were dead.

15. I wanted to hurt myself.

16. I was tired all the time.

17. I did not like myself.

18. I lost a lot of weight without trying to.

19. I had a lot of trouble getting to sleep.

20. I could not focus on the important things. 


\section{Appendix F}

\section{Life Values Inventory (LVI; Schonwetter et al., 1996)}

Below are some values that individuals may find important to them with regard to medical decision making at end-of-life. Please use the below scale to indicate the extent you think that your partner's values are similar to your own.

$\begin{array}{cccc}1 & 2 & 3 & 4 \\ \text { (exactly the opposite of me) } & & \text { (somewhat similar to me) } & \text { (exactly the same as me ) }\end{array}$

1. To preserve good quality of life, even if one doesn't live as long.

2. To live as long as possible, regardless of the quality of life.

3. To maintain the capacity to think clearly.

4. To feel safe and secure.

5. To be able to make one's own decisions.

6. To avoid being a burden on one's family.

7. To leave good memories of one's last days to loved ones.

8. To be with loved ones before dying.

9. To avoid pain and suffering.

10. To experience a comfortable dying process.

11. To be treated with dignity when unable to speak for oneself.

12. To be treated with respect.

13. To be treated in accordance with one's religious beliefs. 


\section{Appendix G}

\section{Quality of Life Values Inventory (QLVI; Cohen-Mansfield, Droge, \& Billig, 1992)}

For each of the following values statements, please use the scale below to indicate the extent to which you think that your partner's values are similar to your own.

1

(exactly the opposite of me)
2
4 (somewhat similar to me)
5 (exactly the same as me )

1. I'd rather not live than be a burden on anyone else.

2. Quality of life is more important than preservation of life.

3. At the end of my life, other people will have the right to live their own lives; they will have taken care of me long enough.

4. Life must be preserved at any cost.

5. At the end of my life, I should think of myself first; if I need help, others will take care of me. 


\section{Appendix $\mathbf{H}$ \\ Interpersonal Reactivity Index (IRI; Davis, 1980)}

Please use the below scale to indicate how much you agree with each statement.

$\begin{array}{ccccc}1 & 2 & 3 & 4 & 5 \\ \text { (strongly disagree) } & & \text { (neither agree nor disagree) } & & \text { (strongly agree) }\end{array}$

1. When I am reading an interesting story or novel, I imagine how I would feel if the events in the story were happening to me.

2. I really get involved with the feelings of the characters in a novel.

3. I am usually objective when I watch a movie or play, and I don't often get completely caught up in it.

4. After seeing a play or movie, I have felt as though I were one of the characters.

5. I daydream and fantasize, with some regularity, about things that might happen to me.

6. Becoming extremely involved in a good book or movie is somewhat rare for me.

7. When I watch a good movie, I can very easily put myself in the place of a leading character.

8. Before criticizing somebody, I try to imagine how I would feel if I were in their place.

9. If I'm sure I'm right about something, I don't waste much time listening to other people's arguments.

10. I sometimes try to understand my friends better by imagining how things look from their perspective.

11. I believe that there are two sides to every question and try to look at them both.

12. I sometimes find it difficult to see things from the "other guy's" point of view.

13. I try to look at everybody's side of a disagreement before I make a decision.

14. When I'm upset at someone, I usually try to "put myself in his shoes" for a while.

15. When I see someone being taken advantage of, I feel kind of protective toward them.

16. When I see someone being treated unfairly, I sometimes don't feel very much pity for them.

17. I often have tender, concerned feelings for people less fortunate than me.

18. I would describe myself as a pretty soft-hearted person.

19. Sometimes I don't feel sorry for other people when they are having problems.

20. Other people's misfortunes do not usually disturb me a great deal.

21. I am often quite touched by things that I see happen.

22. When I see someone who badly needs help in an emergency, I go to pieces.

23. I sometimes feel helpless when I am in the middle of a very emotional situation.

24. In emergency situations, I feel apprehensive and ill-at-ease.

25 . I am usually pretty effective in dealing with emergencies.

26. Being in a tense emotional situation scares me.

27. When I see someone get hurt, I tend to remain calm.

28. I tend to lose control during emergencies. 


\section{Appendix I}

\section{Health Opinion Survey (HOS; Krantz, Baum, \& Wideman, 1980)}

Please use the below scale to indicate how much you agree with each statement.

$\begin{array}{ccccc}1 & 2 & 3 & 4 & 5 \\ \text { (strongly disagree) } & & \text { (neither agree nor disagree) } & & \text { (strongly agree) }\end{array}$

1. Except for serious illness, it's generally better to take care of your own health than to seek professional help.

2. It is better to rely on the judgements of doctors (who are the experts) than to rely on "common sense" in taking care of your own body.

3. Clinics and hospitals are good places to go for help since it's best for medical experts to take responsibility for health care.

4. Learning how to cure some of your own illness without contacting a physician is a good idea.

5. It's almost always better to seek professional help than to try to treat yourself.

6. Learning how to cure some of your illnesses without contacting a physician may create more harm than good.

7. Recovery is usually quicker under the care of a doctor or nurse than when patients take care of themselves.

8. If it costs the same, I'd rather have a doctor or nurse give me treatments than to do the same treatments myself.

9. It is better to rely less on physicians and more on your own common sense when it comes to caring for your body. 


\section{Appendix J}

\section{Reluctance to Burden Others Scale (RBO; Winter \& Parks, 2012)}

Below are some values that individuals may find important to them with regard to medical decision making at end-of-life. Please use the below scale to indicate the extent you think that your partner feels these are important.

1

(not at all important)
2
3

(somewhat important)
4

5

(very important)

1. Avoiding burdening family and friends emotionally as a result of medical treatment decisions

2. Avoiding burdening family and friends financially as a result of medical treatment decisions

3. Avoiding being dependent on others. 


\section{Appendix K}

Correlations between social norms, decision-making confidence, agreement scores, and intervention scores

$\begin{array}{ccccc} & \begin{array}{c}\text { Social } \\ \text { Norms }\end{array} & \begin{array}{c}\text { Decision-making } \\ \text { Confidence }\end{array} & \begin{array}{c}\text { Agreement } \\ \text { Score } \\ .20^{*}\end{array} & \begin{array}{c}\text { Intervention } \\ \text { Score }\end{array} \\ \begin{array}{c}\text { Social Norms } \\ \text { Decision-making }\end{array} & .11 & .11 & .13 & .33^{* *} \\ \quad \text { Confidence } & & & & .07 \\ \text { Agreement Score } & .20^{*} & .13 & .41^{* *} & .41^{* *} \\ \text { Intervention Score } & .33^{* *} & .07 & .4\end{array}$

Note. ${ }^{* *} \cdot p<.01(2$-tailed $)$

Intervention Score $=$ higher scores indicate stronger preferences for intensive interventions

Social Norms $=$ higher scores indicate perceiving interventions as more socially acceptable among one's family and friends

Table 1 
Surrogate demographic characteristics.

\begin{tabular}{|c|c|c|}
\hline Characteristic & $N$ & $\%$ \\
\hline \multicolumn{3}{|l|}{ Sex } \\
\hline Female & 116 & $75.3 \%$ \\
\hline Male & 38 & $24.7 \%$ \\
\hline \multicolumn{3}{|l|}{ Race/ethnicity } \\
\hline White/Caucasian (not Hispanic) & 131 & $85.1 \%$ \\
\hline Black/African-American & 9 & $5.8 \%$ \\
\hline Asian-American & 9 & $5.8 \%$ \\
\hline Hispanic & 3 & $1.9 \%$ \\
\hline Native American/Pacific Islander & 1 & $.6 \%$ \\
\hline Mixed & 1 & $.6 \%$ \\
\hline \multicolumn{3}{|l|}{ Religion } \\
\hline Agnostic & 4 & $2.6 \%$ \\
\hline Atheist & 9 & $5.8 \%$ \\
\hline Christian & 89 & $57.8 \%$ \\
\hline Jewish & 3 & $1.9 \%$ \\
\hline Muslim & 3 & $1.9 \%$ \\
\hline Other & 4 & $2.6 \%$ \\
\hline Protestant & 5 & $3.2 \%$ \\
\hline Roman Catholic & 29 & $18.8 \%$ \\
\hline Seventh-Day Adventist & 2 & $1.3 \%$ \\
\hline Spiritual but not religious & 5 & $3.2 \%$ \\
\hline
\end{tabular}




\section{Marital Status}

Single

Married/committed relationship

Divorced

Separated

Widowed
$9 \quad 5.8 \%$

$139 \quad 90.3 \%$

$2 \quad 1.3 \%$

$1 \quad .6 \%$

$3 \quad 1.9 \%$

Table 2

Patient demographic characteristics. 


\begin{tabular}{|c|c|c|}
\hline Characteristic & $N$ & $\%$ \\
\hline \multicolumn{3}{|l|}{ Sex } \\
\hline Female & 44 & $28.8 \%$ \\
\hline Male & 109 & $71.2 \%$ \\
\hline \multicolumn{3}{|l|}{ Race/ethnicity } \\
\hline White/Caucasian (not Hispanic) & 132 & $86.3 \%$ \\
\hline Black/African-American & 7 & $4.6 \%$ \\
\hline Asian-American & 10 & $6.5 \%$ \\
\hline Hispanic & 2 & $1.3 \%$ \\
\hline Native American/Pacific Islander & 1 & $.7 \%$ \\
\hline Mixed & 1 & $.7 \%$ \\
\hline \multicolumn{3}{|l|}{ Religion } \\
\hline Agnostic & 6 & $3.9 \%$ \\
\hline Atheist & 14 & $9.2 \%$ \\
\hline Christian & 89 & $58.2 \%$ \\
\hline Jewish & 1 & $.7 \%$ \\
\hline Muslim & 4 & $2.6 \%$ \\
\hline Other & 2 & $1.3 \%$ \\
\hline Protestant & 9 & $5.9 \%$ \\
\hline Roman Catholic & 22 & $14.4 \%$ \\
\hline Seventh-Day Adventist & 3 & $2.0 \%$ \\
\hline Spiritual but not religious & 3 & $2.0 \%$ \\
\hline
\end{tabular}




\section{Marital Status}

\begin{tabular}{lcc} 
Single & 6 & $3.9 \%$ \\
Married/committed relationship & 134 & $87.6 \%$ \\
Divorced & 7 & $4.6 \%$ \\
Separated & 3 & $2.0 \%$ \\
Widowed & 3 & $2.0 \%$ \\
& & \\
\hline
\end{tabular}


Table 3

Percent of patient-surrogate pairs who agreed on each decision vignette.

\begin{tabular}{lc}
\hline Treatment Vignette & \% Agreement \\
\hline Ventilation & $75.6 \%$ \\
CPR & $83.6 \%$ \\
Feeding Tube & $76.1 \%$ \\
Chemotherapy & $81.3 \%$ \\
Amputation & $82.8 \%$ \\
Cardiac Bypass & $88.8 \%$ \\
Dialysis & $85.1 \%$ \\
\hline
\end{tabular}


Table 4

Correlations between surrogate intrapersonal and interpersonal variables, agreement scores, and intervention selection.

\begin{tabular}{|c|c|c|c|c|c|c|c|c|c|c|c|c|c|c|c|c|c|}
\hline & Agreement & Age & $\begin{array}{l}\text { Physical } \\
\text { Health }\end{array}$ & Education & COVID worry & QLVI/LVI & HOS & TIMPS & STAI & IRI & CESD & DUREL & RBO & CBESS & Tx Under & Tx Disc & $\begin{array}{l}\text { Intervention } \\
\text { Score }\end{array}$ \\
\hline Agreement & 1 & -.02 & -.00 & -.08 & .09 & $.26^{* * *}$ & .03 & $.17^{*}$ & .06 & $.25^{*}$ & .10 & $.24 * *$ & $.18^{*}$ & .05 & .10 & .12 & $.41^{* *}$ \\
\hline Age & -.02 & 1 & -.09 & .12 & -.10 & -.10 & .06 & -.02 & $-.20^{*}$ & .15 & -.10 & .02 & .07 & -.04 & .00 & .05 & -.13 \\
\hline $\begin{array}{l}\text { Physical } \\
\text { Health }\end{array}$ & & & 1 & & & & & & & & & & & & & & \\
\hline Education & -.08 & -.08 & -.04 & 1 & -.12 & -.08 & -.03 & -.06 & -.05 & -.16 & -.10 & -.03 & .01 & -.08 & -.11 & $-.20 *$ & -.05 \\
\hline $\begin{array}{l}\text { COVID } \\
\text { worry }\end{array}$ & .09 & -.10 & -.04 & -.12 & 1 & .02 & .05 & $.16^{*}$ & $.30 * *$ & .11 & $.31^{* *}$ & $-.16^{*}$ & -.03 & -.06 & -.15 & $-.16^{*}$ & $.24 * *$ \\
\hline QLVI/LVI & $.26^{* *}$ & -.10 & .06 & -.08 & .02 & 1 & $-.25^{* *}$ & $.42^{* *}$ & $-.26 * *$ & $.57 * *$ & $-.24 * *$ & $.23^{* *}$ & $.64 * *$ & $.57 * *$ & $.36^{* *}$ & $.20^{* *}$ & .06 \\
\hline $\begin{array}{l}\text { QLVI/LVI } \\
\text { Diff. }\end{array}$ & $.22^{* *}$ & -.13 & .03 & -.07 & -.04 & $.71^{* *}$ & $-.24^{* *}$ & .15 & $-.21^{*}$ & $.50^{* *}$ & $-.32^{* *}$ & $.20^{*}$ & $.44^{* *}$ & $.41^{* *}$ & $.31^{* *}$ & .12 & -.01 \\
\hline HOS & .03 & .06 & $-.17 *$ & -.03 & .05 & $-.26^{* *}$ & 1 & -.11 & $.35 * *$ & $-.42 * *$ & $.34 * *$ & .07 & -14 & $-.50^{* *}$ & $-.23 * *$ & -.03 & $-.18 *$ \\
\hline TIMPS & $.17 *$ & -.02 & .08 & -.06 & $.16^{*}$ & $.42 * *$ & -.11 & 1 & .04 & $.24 * *$ & $.20 *$ & $.20 *$ & $.36^{* *}$ & $.41^{* *}$ & .14 & $.20 *$ & .14 \\
\hline STAI & .06 & $-.20 *$ & -.05 & -.04 & $.30^{* *}$ & $-.26^{* *}$ & $.36^{* *}$ & .04 & 1 & $-.20^{*}$ & $.71 * *$ & .01 & $-.26 * *$ & $-.50^{* *}$ & $-.31^{* *}$ & -.05 & .06 \\
\hline IRI & $.25 * *$ & -.15 & .05 & -.16 & .11 & $.57 * *$ & $-.42 * *$ & $.24 * *$ & $-.20 *$ & 1 & -.14 & .13 & $.33^{* *}$ & $.55^{* *}$ & $.16^{*}$ & $.21 * *$ & $.16^{*}$ \\
\hline CESD & .10 & -.10 & .05 & -.10 & $.31 * *$ & $-.24 * *$ & $.34 * *$ & .19 & $.71 * *$ & -.14 & 1 & .10 & $-.20^{*}$ & $-.37 * *$ & $-.32^{* *}$ & .12 & .07 \\
\hline DUREL & $.24 * *$ & .02 & -.06 & -.03 & $.16^{*}$ & $.23 * *$ & .07 & $.20 *$ & .01 & .13 & .11 & 1 & $.20^{*}$ & -.04 & $.19^{*}$ & $.38^{* *}$ & .08 \\
\hline RBO & $.18^{*}$ & .07 & -.04 & .01 & -.03 & $.64 * *$ & -.14 & $.36 * *$ & $.26 * *$ & $.33 * *$ & $-.20 *$ & $.20 *$ & 1 & $.41 * *$ & $.24 * *$ & $.25 * *$ & -.10 \\
\hline CBESS & .04 & -.04 & .05 & -.08 & -.06 & $.57 * *$ & $-.50^{* *}$ & $.41^{* *}$ & $-.50 * *$ & $.55^{* *}$ & $-.37^{* *}$ & -.04 & $.41 * *$ & 1 & $.40^{* *}$ & $.19^{*}$ & .07 \\
\hline Tx Under & .09 & .00 & $.18^{*}$ & -.11 & -.15 & $.37 * *$ & $-.23 * *$ & .14 & $-.31 * *$ & $.16^{*}$ & $-.32^{* *}$ & $.19 *$ & $.24 * *$ & $.40 * *$ & 1 & .11 & .16 \\
\hline $\begin{array}{l}\text { Intervention } \\
\text { Score }\end{array}$ & $.41 * *$ & -.13 & $.20^{*}$ & -.05 & $.24 * *$ & .06 & $-.18^{*}$ & .14 & .06 & $.16^{*}$ & .07 & .08 & -.10 & .07 & .16 & -.01 & 1 \\
\hline Tx Disc & .12 & .05 & .11 & $-.20^{*}$ & $.16^{*}$ & $.20^{*}$ & $-.03 *$ & $.20^{*}$ & -.05 & $.21^{* *}$ & .12 & $.39 * *$ & $.25^{*}$ & $.20 *$ & .11 & 1 & -.01 \\
\hline
\end{tabular}

Note. ${ }^{* *} . p<.01(2$-tailed $)$

QLVI/LVI = Quality of Life Values Inventory/Life Values Inventory

QLVI/LVI Diff = Difference between surrogates' and patients' ratings of perceived similarity on end-of-life values

HOS = Health Opinion Survey

TIMPS $=$ Trust in Medical Profession Scale

STAI $=$ State-Trait Anxiety Inventory

IRI = Interpersonal Reactivity Index

$\mathrm{CESD}=$ Center for Epidemiological Studies_-Depression

DUREL $=$ Duke University Religion Index

CBESS $=$ Communication-Based Emotional Support Scale

Tx Under $=$ Treatment understanding score

Tx Disc. $=$ Prior discussion of treatment preferences

Intervention Score $=$ higher scores indicate stronger preferences for intensive interventions 
Table 5

Means and standard deviations for key study variables, as reported by surrogates.

\begin{tabular}{lccc}
\hline Variable & Range of possible scores & $M$ & $S D$ \\
\hline Empathy (IRI) & $28-140$ & 95.17 & 11.13 \\
Trust in the medical profession (TIMPS) & $11-55$ & 38.78 & 6.82 \\
Religiosity (DUREL) & $6-30$ & 17.29 & 5.60 \\
Anxiety (STAI-T) & $20-80$ & 50.80 & 9.83 \\
COVID-19-related anxiety & $1-10$ & 7.76 & 1.00 \\
Desire for autonomy on decisions (HOS) & $9-81$ & 23.95 & 5.24 \\
Depression (CESD-R) & $20-60$ & 23.76 & 5.88 \\
Emotional support from partner (CBESS) & $13-65$ & 39.00 & 4.65 \\
Communication with partner about preferences & $1-4$ & 3.04 & .75 \\
Self-rated physical health & $18-90$ & 70.02 & 11.13 \\
Understanding of treatment options & $7-35$ & 25.49 & 5.88 \\
Partner's reluctance to burden others (RBO) & $5-15$ & 11.34 & 2.40 \\
Values similarity to partner (QLVI/LVI) & & 7.63 &
\end{tabular}


Table 6

Results of the multiple regression analysis using significant correlates to predict accuracy.

$\begin{array}{llll} & B & \text { SE } B & p \\ \text { TIMPS } & .01 & .05 & .60 \\ \text { DUREL } & .03 & .02 & .07 \\ \text { IRI } & .02 & .01 & .10 \\ \text { RBO } & .00 & .05 & .89 \\ \text { QLVI/LVI } & .01 & .01 & .41 \\ \text { QLVI/LVI Diff } & .00 & .01 & .78\end{array}$

QLVI/LVI = Quality of Life Values Inventory/Life Values Inventory

QLVI/LVI Diff = Difference between surrogates' and patients' ratings of perceived similarity on end-of-life values TIMPS $=$ Trust in Medical Profession Scale

$\mathrm{RBO}=$ Reluctance to Burden Others Scale

IRI = Interpersonal Reactivity Index

DUREL $=$ Duke University Religion Index 
